\title{
NegoManage: A System for Supporting Bilateral Negotiations
}

\author{
Jakub Brzostowski • Tomasz Wachowicz
}

Published online: 18 June 2013

(C) The Author(s) 2013. This article is published with open access at Springerlink.com

\begin{abstract}
In this paper we present the NegoManage system, which aims at supporting the bilateral negotiation during all negotiation phases. The support includes the problem structure identification, the analysis of individual preferences of both parties, the messaging and offers exchange and the post-negotiation improvements of the agreement. The preference analysis is supported with a novel mechanism involving the specification of the classes of alternatives' quality that represent particular levels of potential satisfaction from accepting this alternative as the negotiation solution. The consistency of preferences is also checked. The actual negotiation phase is performed in a typical way, namely the negotiators exchange multiple offers and messages. The novelty introduced in this phase is the mechanism for profiling the negotiators based on the classification of exchanged messages. The post-negotiation optimization phase employs the concept of a bargaining solution for improving the solution obtained in the previous negotiation phase. We present the way the mechanisms proposed work using simple numerical examples.
\end{abstract}

Keywords Negotiation support systems · Negotiation analysis ·

Preference analysis · Reputation systems · Negotiation outcome optimization

\footnotetext{
J. Brzostowski $(\varangle)$

Institute of Mathematics, Silesian University of Technology, Kaszubska 23,

44-100 Gliwice, Poland

e-mail: jakub.brzostowski@polsl.pl

T. Wachowicz

Department of Operations Research, University of Economics in Katowice,

1 Maja 50, 40-287 Katowice, Poland

e-mail: tomasz.wachowicz@ue.katowice.pl
} 


\section{Introduction}

The negotiation support systems (NSS), such as Inspire (Kersten and Noronha 1999), Negoisst (Schoop et al. 2003), SmartSettle (Thiessen and Soberg 2003) or TOBANS (Wachowicz and Błaszczyk 2012), provide negotiators with a variety of tools that can help them in accomplishing all the negotiation tasks that appear during a negotiation process. Since negotiation is commonly perceived as a decision making process (Thompson 1998), it is not difficult to find that the vast majority of negotiation tasks involves decision making. Kersten and Lai (2007) identify 23 major functions of NSS, and 14 of them are directly related to decision aspects of the negotiation process. The remaining ones are linked to other aspects of the negotiation process, such as: communication, process management and knowledge storage and use. The decisionmaking-related functions allow to accomplish such negotiator's tasks as:

- negotiation problem formulation,

- identification of goals and objectives,

- definition of BATNA and reservation levels,

- preference elicitation,

- computation and verification of parameters of the negotiation problem model,

- assessment of decision space,

- analysis of feasible solutions,

- formulation and evaluation of strategies and tactics (for both parties),

- construction and verification of models of negotiation counterparts,

- counterpart analysis,

- offers and messages construction,

- offers and messages evaluation,

- history (data) evaluation and presentation,

- agreement analysis.

To fulfill these functions NSS need to operate with the formal models that describe: the negotiation problem, the negotiator's preferences and the negotiation process. However, implementing a particular formal model imposes on the system's users the necessity of following a formal negotiation protocol and operating with supporting methods and tools that are coherent with this model. Naturally, it is assumed that the users understand the methodology applied, know the consequences of using it and are able to correctly interpret the results the methodology provides them with. Hence, in a field of problem formulation and preference elicitation the Simple Additive Weighting (SAW) is commonly implemented (see Keeney and Raiffa 1976) It was applied in such negotiation support systems as Inspire, SmartSettle and Negoisst, however the last one had also been equipped with the alternative tools for analyzing negotiators' preferences. SAW derives from Multiple Attribute Value Theory (MAVT) (see Keeney and Raiffa 1976) and is considered to be one of the simplest decision making approaches. From the pragmatic point of view it yields close approximations of the decision model to the "true" problem description (Edwards 1977; Farmer 1987). However, some recent research indicates that despite its simplicity, SAW scores are quite often misinterpreted or misused by the negotiators (see Wachowicz and Kersten 2009; and the results of GRIN project Paradis et al. 2010). Furthermore, in SAW the 
issues weights are simply assigned by the decision maker instead of being elicited (Forman and Selly 2001), which may be troublesome, especially to negotiators who are not familiar with decision making methods or tools and may result in further misunderstandings and misinterpretations (Schenkerman 1991; Zhang et al. 1992). Yet the issue weighting is a crucial element of the preference analysis which heavily influences the resulting scoring system, and therefore it should be conducted thoroughly and accurately. This observation creates a need to evaluate different multiple criteria decision making (MCDM) methods in order to check if such methods can be applied in the NSS for forming the negotiation offers scoring system.

According to some prenegotiation theories (see Zartman 1989; Stein 1989) an effective negotiator should identify not only the negotiation problem itself, but also their negotiation counterpart. When counterpart analysis is considered, NSSs need to be able to compute somehow bargaining profiles of negotiators. Such a profile indicates the negotiator's approach towards conflict and counterpart, and may be useful while performing the mediating role by the NSS. Moreover, in electronic negotiations the negotiators are usually anonymous, and such a profile constitutes a small portion of information that can be displayed to all potential partners so the anonymity is in some way reduced. Examples of tools used for profile recognition are Thomas-Kilmann Conflict mode instrument (TKI) (Kilmann and Thomas 1983) or Myers-Briggs Type Indicator (MBTI) (Myers and McCaulley 1985). These tools are psychometric instruments requiring the users to fill in a questionnaire that is then scored, which leads to the identification of the psychological profile of the potential negotiators. Such tools are widely used in research and practice, since they measure the negotiators' approach towards conflict situations (see Wood and Bell 2008; Wachowicz and Wu 2010). However, these tools cannot be considered fully reliable since the questionnaire results are not stable. It turns out that less than $50 \%$ of the subjects score the same when asked to answer the questionnaire once again after some weeks (Gardner and Martinko 1996). Moreover, some users find the tests frustrating, since answering the series of questions may be both time consuming and troublesome. Therefore, alternative tools and methods for negotiators profiling are required that could allow negotiators to easily identify both their own and their counterpart's negotiation profile and hence help them with adequate preparation of the negotiation strategies and tactics.

Another important functionality of the NSS is the mediation activity that allows for the improvement of the compromise obtained by the negotiators in the actual negotiation phase. The post-optimization phase requires the verification of the compromise in terms of its Pareto efficiency, and it aims to mutually improve the parties' outcomes. Since the NSS has the ability to confront the preferences of both parties it can compute the Pareto efficient frontier consisting of potential contracts dominating the compromise obtained. Such an analysis is conducted by Inspire system (Kersten and Noronha 1999) and results in the list of potential improvements that are presented to the parties for renegotiation of the compromise they negotiated beforehand. However, the NSS can act more proactively at this stage of analysis in order to determine the single fair improvement according to certain concepts of the game-theoretical bargaining solutions.

Since many models and algorithms currently applied in NSSs have various drawbacks and limitations (both of technical and usable nature), it seems vital to develop 
new models that will help to overcome the methodological problems as well as to improve the use and usefulness of the software tools in negotiation. In this paper we present a new NSS called NegoManage (NM) that supports bilateral negotiations, and we extend the initial discussion to the system introduced in the earlier work by Brzostowski and Wachowicz (2012). The system itself is an original supportive tool that uses a novel preference elicitation approach based on MAVT but simultaneously rejects the decompositional approach in defining the negotiator's preferences. It implements some ideas of the conjoint analysis aiming at building the scoring system of the negotiation offers based on the examples of offers formulated by the negotiator in the prenegotiation analysis. We also propose a method for measuring the consistency of the negotiator's responses and declarations given in the prenegotiation phase during the process of building the scoring system of the negotiation offers, which we use to check whether such a system adequately describes the negotiator's true preferences. NegoManage is also equipped with the integral reputation system that allows for identifying the negotiators' profiles without employing any psychometric tool. The profiles are computed on the basis of messages exchanged, that are weighted and evaluated by the parties within the negotiation process. NegoManage may be also used in the postnegotiation optimization phase to find improvements of the negotiated agreement. We have proposed an original simple mechanism that stems from the bargaining solutions proposed by Raiffa (1982) and Gupta and Livne (1988).

The paper consists of four more sections, in which we discuss the novel formal models implemented in NSS NegoManage that are responsible for accomplishing its three major functions: problem definition and offers evaluation (decision support); communication and counterpart recognition; and post-negotiation optimization. In Sect. 2 we present the formal model responsible for preference elicitation and building the scoring system of the negotiation offers. We discuss the basic idea of preference elicitation applied that implements the notion of indifference surfaces and then propose an additional algorithm for the automatic construction of such surfaces. Then the notion of probability distributions over indifference surfaces is introduced, since it is used for building the negotiation offers scoring system. We also introduce a simple method for verifying the preference consistency based on Jaccard's index. In Sect. 3 we present briefly the model used for negotiator profiling and building the reputation system for NegoManage negotiators. It is based on the speech act taxonomy dedicated to the negotiation context. We present the general philosophy of building such a system as well as the formal scoring algorithm that is used for determining the negotiator's profile when two major negotiator's characteristics are considered: cooperativeness and assertiveness. In Sect. 4 we discuss the formal model used in the post-negotiation phase for improving the negotiation compromise achieved by the parties. It aims at finding an improvement of the compromise represented in the scoring space of both negotiators that will be as close as possible to the efficient frontier, here not defined explicitly. In Sect. 5 we present NegoManage as the software solution showing its general configuration and describing its major modules that implement the formal model introduced before.

In the appendixes the examples of using the proposed models are given. In Appendix 7.1 we show how the indifference surface based scoring system may be used for the evaluation of the negotiation offer. In Appendix 7.2 we show an example of evaluation 
of the communication thread that is used by the profiling mechanism to recalculate the profiles of the negotiators involved in this communication process. In Appendix 7.3 an example of searching for the improvements of the negotiation agreement is presented.

\section{Negotiation Offers Scoring System}

\subsection{Negotiation Problem Definition and Preference Elicitation}

One of the major functionality of NSSs is supporting negotiators in preference elicitation and building the systems for scoring the negotiation offers. This scoring system helps negotiators to evaluate each incoming or self-built offer, compare the sequence of offers (concession paths) and make the final decision of accepting or rejecting any negotiation contract. The process of preference analysis is supported by NegoManage system in a specific way, namely it employs two novel concepts characteristic to the proposed preferences model, i.e. the concept of indifference surfaces and the concept of linguistic utility scale (Brzostowski and Wachowicz 2011). The fundamental ideas of the preference model we propose is however derived from MAVT and consequently we assume that the global preferences may be represented linearly by means of the linear scoring (value) functions.

We assume here that, according to the theory of negotiation, the parties meet each other for prenegotiation talks, during which they commonly define the negotiation problem (see Zartman 1989; Raiffa et al. 2003), so the set of $m$ negotiation issue is specified in the following form:

$$
G=\left\{g_{1}, \ldots, g_{m}\right\}
$$

Furthermore, they specify the negotiation space by defining the feasible ranges of resolution levels for all the options.

In contrast to SAW-based scoring systems we do not require the negotiation problem to be defined in discrete form by means of the finite set of feasible negotiation offers. Quite the contrary, we allow all the quantitative issues to be defined in form of continuous variables. According to the calculation requirements, all the resolution levels of qualitative issues need to be represented by means of their numerical equivalents (an interval-scale representation is required). Thus each negotiation offer $a$ can be represented in the form of a full package specifying the resolution levels (options) for all negotiation issues and may be formally denoted as

$$
a=\left(g_{1}(a), \ldots, g_{m}(a)\right)
$$

The preference elicitation in NegoManage system derives from the conjoint measurement (see Luce and Tukey 1964; Krantz et al. 1971) and hence is not of decompositional nature. It is assumed that negotiators define first the set of indifference surfaces describing the various categories of negotiation offers

$$
R S=\left(R S, \ldots, R S_{n}\right)
$$


and evaluate them, by assigning a numerical score to each indifference surface. ${ }^{1}$ Thus we assume that there is a negotiator-specific scoring rule $v$, not yet explicitly defined, that assigns a numerical score $u_{i}$ to each $R S_{i} \in R S$. We may denote it formally as

$$
v\left(R S_{i}\right)=u_{i}
$$

This score $u_{i}$ is the numerical equivalent of the quality of the offers from the $i$ th category.

Finally, the negotiators need to create the examples of offers (alternatives) for each indifference surface declared. In other words, they have to provide the system with the sets of offers that represent the consecutive categories. As a result we obtain the indifference surface specification in the form

$$
R S_{i}=\left\{a_{1}^{i}, \ldots, a_{n_{i}}^{i}\right\}
$$

where every two alternatives belonging to the set $R S_{i}$ are mutually indifferent $\left(a_{k}^{i} \sim\right.$ $a_{l}^{i}$ ). We will assume that each negotiation offer belonging to $R S_{i}$ has been assigned the quality level (score) of $R S_{i}$. Thus we obtain

$$
v\left(a_{k}^{i}\right)=v\left(R S_{i}\right)=u_{i}: \forall a_{k}^{i} \in R S_{i} .
$$

The complete definition of all $R S_{i} \in R S$ together with the corresponding $u_{i}$ values constitute the structure of preference of the focal negotiator and will be used to build the negotiation offers scoring system that allows to score any feasible offer during the actual negotiation phase.

\subsection{Automated Complement of the Indifference Surface}

The process of defining the preferences by the negotiator may be troublesome and time consuming, since it requires the generation of many representative alternatives for each indifference surface $R S_{i}$. Therefore, a supportive procedure should be proposed to speed up this process. It appears that parts of indifference surfaces may be generated automatically under certain assumptions about the preference structure. According to the research of Keeney and Raiffa (1976) all the issues considered in the analysis are mutually preferentially independent, therefore the scoring function can be represented in additive form. By assuming the additive form of scoring function we obtain the condition of mutual independent preference of all issues. This condition allows us to apply a procedure of automated generation of indifference surfaces. Under the assumption of additive structure of preferences the procedure for generating the representative of the surfaces may be represented by the following algorithm:

1. We start from the surface with the lowest possible utility level. Let us assume that the surfaces are ordered according to increasing scores $u_{i}$, so $\mathrm{u}_{i}$ denotes the

\footnotetext{
1 NegoManage Decision Support Unit has implemented an extender linguistic scale to facilitate the process of evaluation of the indifference surfaces (see Sect. 5).
} 
score assigned to the worst (least preferred) indifference surface. Let us assume further that the negotiator chooses initially the resolution levels of each negotiation issue $\left(x_{1}^{1}, \ldots, x_{1}^{m}\right)$ (which is a simplified description of some alternative $a_{1}$, and therefore $\left.g_{i}\left(a_{1}\right)=x_{1}^{i}\right)$ that form the marginal alternative of the lowest possible score, such that

$$
v\left(x_{1}^{1}, \ldots, x_{1}^{m}\right)=u_{1}
$$

2. Then the negotiator is asked to input the marginal alternatives for the second indifference surface $R S_{2}$ of the following forms:

$$
\begin{gathered}
\left(x_{2}^{1}, x_{1}^{2}, \ldots, x_{1}^{m}\right) \\
\left(x_{1}^{1}, x_{2}^{2}, \ldots, x_{1}^{m}\right) \\
\vdots \\
\left(x_{1}^{1}, x_{1}^{2}, \ldots, x_{2}^{m}\right)
\end{gathered}
$$

The rule for creating marginal alternatives is that all issues have to be set to minimal values $x_{1}^{j}$ except for the one issue which has been set to $x_{2}^{j}$. Since the next $n$ marginal alternatives built according to the formula (8) form the next indifference surface, they too have been assigned the score of this surface, i.e.

$$
v\left(x_{2}^{1}, x_{1}^{2}, \ldots, x_{1}^{m}\right)=v\left(x_{1}^{1}, x_{2}^{2}, \ldots, x_{1}^{m}\right)=\ldots v\left(x_{1}^{1}, x_{2}^{1}, \ldots, x_{2}^{m}\right)=u_{2}
$$

3. To build $R S_{3}$, new alternatives are built based on the knowledge gained during the generation of $R S_{2}$. The alternatives for the third surface are created in the following way:

- The marginal points of the first two surfaces are used: $x_{1}^{1}, \ldots, x_{1}^{m}, x_{2}^{1}, \ldots, x_{2}^{m}$.

- The set $S_{3}$ is automatically created such that

$$
S_{3}=\left\{\left(x_{k_{1}}^{1}, \ldots, x_{k_{m}}^{m}\right) \mid \sum_{j=1}^{m} k_{j}=m+2 \wedge k_{j} \in\{1,2\}\right\} .
$$

The set $S_{3}$ constitutes a part of the third indifference surface.

4. $S_{3}$ is presented to the negotiator, who is asked to add to $S_{3}$ marginal alternatives consistent in terms of overall quality with the previously generated alternatives:

$$
\begin{gathered}
\left(x_{3}^{1}, x_{1}^{2}, \ldots, x_{1}^{m}\right) \\
\left(x_{1}^{1}, x_{3}^{2}, \ldots, x_{1}^{m}\right) \\
\vdots \\
\left(x_{1}^{1}, x_{1}^{2}, \ldots, x_{3}^{m}\right)
\end{gathered}
$$


These new alternatives should be indifferent to the alternatives generated previously for this surface $S_{3}$. Together they comprise $R S_{3}$ and are given the score of $u_{3}$.

5. We repeat the steps 3 and 4 to build the successive $R S_{i}$, for $i=4, \ldots, l$, where $l$ denotes the last indifference set, for which the negotiator is able to define the representative alternatives using the marginal options $x_{1}^{j}$ (for $j=1, \ldots, m$ ). As before we use:

- the enlarged sets of marginal points $x_{1}^{1}, \ldots, x_{1}^{m}, x_{2}^{1}, \ldots, x_{2}^{m}, \ldots, x_{i-1}^{1}, \ldots$, $x_{i-1}^{m}$.

- the automatically generated sets $S_{i}$ such that:

$$
S_{i}=\left\{\left(x_{k_{1}}^{1}, \ldots, x_{k_{m}}^{m}\right) \mid \sum_{j=1}^{m} k_{j}=m+i-1 \wedge k_{j} \in\{1,2, \ldots, i-1\}\right\} .
$$

- the marginal alternatives added by the negotiator, of the form:

$$
\begin{gathered}
\left(x_{3}^{1}, x_{1}^{2}, \ldots, x_{1}^{m}\right) \\
\left(x_{1}^{1}, x_{3}^{2}, \ldots, x_{1}^{m}\right) \\
\vdots \\
\left(x_{1}^{1}, x_{1}^{2}, \ldots, x_{3}^{m}\right)
\end{gathered}
$$

as long as the negotiator is able to build the representative alternatives using the marginal options $x_{1}^{j}$ (for $j=1, \ldots, m$ ).

6. For $R S_{i}$, where $i=l+1, \ldots, n$, the system itself completes the consecutive surfaces automatically by adding to each of them the alternatives in the following way:

$$
S_{i}=\left\{\left(x_{k_{1}}^{1}, \ldots, x_{k_{m}}^{m}\right) \mid \sum_{j=1}^{m} k_{j}=m+i-1 \wedge k_{j} \in\{1,2, \ldots, l\}\right\} .
$$

As the result of this algorithm we obtain a full specification of negotiators' preferences including the last indifference surface $R S_{n}$ that consist of one top-level alternative built with the most preferred options that were declared by the negotiators in the process of automatic complement of all surfaces.

\subsection{Construction of the Scoring System}

Having specified negotiator's preferences we build the final negotiation offers scoring systems, that may be used later on in the actual negotiation phase for the evaluation of incoming alternatives and in the post-negotiation to conduct the improvement analysis of the negotiated agreement. Since we assumed that the negotiation issues are represented numerically by means of continuous variables, we may expect that the 
incoming offers consist of the option values that were not declared by the negotiator during the preference elicitation process. We have to keep in mind that the negotiator had specified only some examples of alternatives of a particular quality level (score/utility) and there can be several other alternatives that could be also assigned to the surface with this score. To overcome this problem we can consider a partial level of belonging to a surface, which can be modeled by the concept of probability. As a result, the probability can be interpreted as the chance of proper assignment of an alternative to the indifference surface. Therefore in the NegoManage system we use formally defined characteristics of indifference surfaces in the form of probability distributions. The probability distribution built for each surface is obtained based on the following postulate:

The closer an alternative under consideration is located to the one that fully belongs to the indifference surface, the higher is the level of probability of proper assignment of this alternative to the surface.

Before the distributions are built, the surfaces are first clustered using hierarchical clustering (Hartigan 1975) and kernel density estimation (Parzen 1962) is used to derive the multi-modal distributions over the surfaces. Full details of this procedure as well as its rationale may be found in the earlier paper by Brzostowski (2011). Here we present the main steps of building the negotiation offers scoring system.

\subsubsection{The Distribution Type Formed Over the Indifference Surface}

Based on the postulate formulated above we formulate the procedure of determining the probability distribution for a particular indifference surface. If we consider any alternative that was not assigned by the negotiator to the surface we can compute its probability of belonging to the surface based on the degree of similarity of this alternative to alternatives fully belonging to the surface (classified by the negotiator to the considered surface). The higher this level of similarity, the higher is the probability of belonging to the surface. Naturally, each alternative classified by the negotiator in the preference elicitation phase will be assigned the probability equal to 1 . This assumption results in peaks located around the alternatives classified and reflecting the shape of the characterizing distribution). Such peaks may be bell-shaped, modeled by multivariate normal distributions. However, there are no substantial or experimentally proved reasons for using any specific type of distribution. When selecting the distribution type for the NegoManage scoring procedure we simply decided to use the distribution which is the most common in other applications. The bell-shaped peaks built around the fully classified alternatives are fused in the next step to form an overall multi-modal distribution characterizing the indifference surfaces. This procedure is commonly known as kernel density estimation (Parzen 1962).

\subsubsection{The Need for Clustering the Indifference Surfaces}

During the peak formation another issue is taken into consideration, namely the commutation of some reference alternative in some regions of the space of feasible alternatives. In cases where reference alternatives are densely located in a small area there 
Fig. 1 Alternatives and the corresponding peaks for defining the indifference surface (set)

Fig. 2 Aggregated peaks for defining the indifference surface (set)
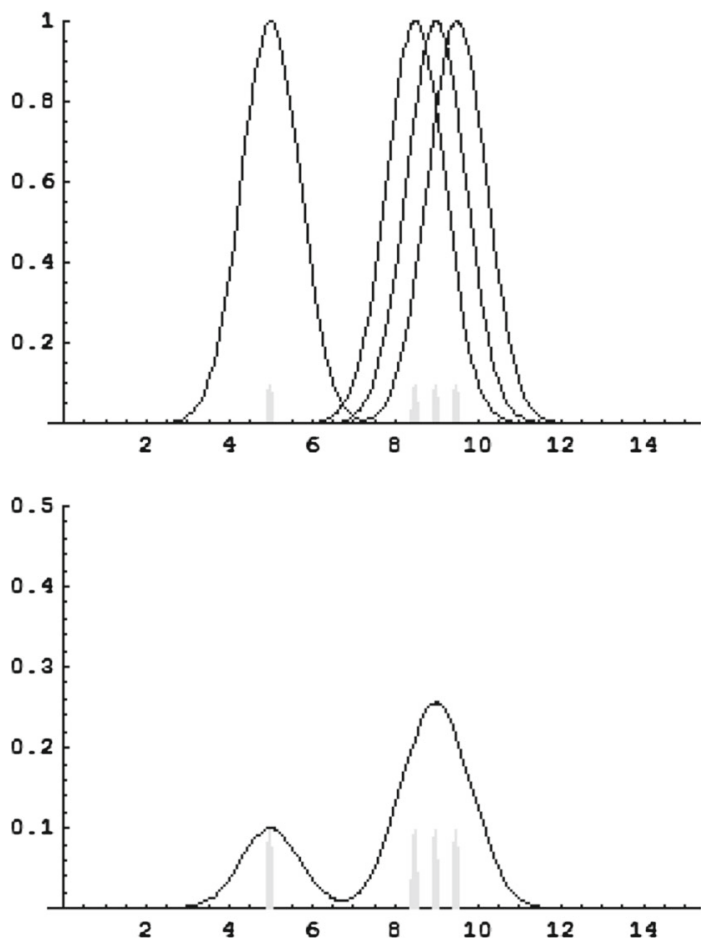

is a need to perform the clustering of the indifference surfaces first and build the peaks over the cumulated groups of alternatives in the next step. For the sake of illustration we consider one-issue scenario in this section. Although such a scenario is impractical we will use it to justify the idea of surface clustering.

The points in Fig. 1 correspond to four alternatives assigned to the surface (set) by the negotiator. For each of the four points bell-shaped peaks have been determined (using the Gaussian distribution). As we can see, three out of four points are closely located to each other. In this case the three peaks highly overlap. By applying the concept of Kernel Density Estimation the probabilistic characteristics of the indifference surface can be described by the following formula:

$$
f_{R S}(x)=\frac{1}{4 \cdot b} \sum_{i=1}^{4} \exp \left(-d_{b}\left(x, m_{i}\right)^{2}\right)=\frac{1}{4 \cdot b} \sum_{i=1}^{4} \exp \left(-\left(\frac{x-m_{i}}{b}\right)^{2}\right) .
$$

where $b$ is the bandwidth defining the span of each peak; the function $d_{b}$ is the distance measure depending on the value of bandwidth; the constant $4 \cdot b$ is the coefficient taking into account the value of bandwidth and the averaging constant; $m_{i}$ are the values of reference points (gray points), i.e. the examples used to form the indifference set; and $x$ is point for which the probability of belonging is computed.

As a result of peak fusion using the averaging formula we obtain the distribution shown in Fig. 2. 
As we can see in Fig. 2, the amount of probability cumulated in the region of the three points, which are close to each other, is quite high in relation to the probability around the single point (first on the left). The fusion of the three highly overlapping peaks causes the occurrence of a peak (in the final distribution) that is much higher than the peak located over the single point. However, it is desirable that the heights of the peaks in the final distribution should not differ very much since the final probability values computed for the fully classified points should indicate their high degree of belonging to the surface. To avoid the situation of unequal probabilities for different reference alternatives we propose to use hierarchical clustering before the construction of peaks and final distribution. The algorithm we use for grouping is agglomerative, meaning that in the first step we have uni-elementary clusters. In the next steps the clusters are successively merged - the number of clusters decreases while their size increases. The merging stops when the maximal distance between the centroid and other alternatives belonging to the clusters reaches the level selected. The details of the clustering of the alternatives within each indifference surface are discussed in an earlier paper by Brzostowski and Wachowicz (2012i).

\subsubsection{The Formal Procedure for Computing the Scoring System}

Knowing the reason for clustering the offers, we can present examples the formal algorithm for determining the surface characteristics. As it is applied in NegoManage system the algorithm consists of the following six steps:

\section{- Step 1.}

Using the hierarchical clustering, the indifference surface $R S_{i}$ is split into groups of alternatives. Let us assume that we have already split the surface into some groups. Given a split of the set $R S_{i}$ into $k$ disjoint subsets $M_{i 1}, M_{i 2}, \ldots, M_{i k}$, the means $m_{i 1}, m_{i 2}, \ldots, m_{i k}$ for all the subsets (clusters) are computed:

\section{- Step 2 .}

Using the means at the current stage the alternatives are reassigned to clusters. Each alternative is assigned to the cluster with the closest mean. We use the Euclidean distance to compute the distance between a representative alternative and the centroid of a cluster.

- Step 3 .

Steps 1 and 2 are repeated until the assignment of the alternatives no longer changes. Such a clustering state is consistent with the convergence condition.

\section{- Step 4.}

With the indifference set clustered, the probability distribution over the set can be built. For each $M_{i j}$ (the $j$ th cluster of the $i$ th indifference set) the multivariate normal distribution is built. Therefore, we use the probability distribution function of the following form:

$$
f_{M_{i j}}(\bar{a})=\frac{1}{(2 \pi)^{k / 2}\left|\Sigma_{i j}\right|^{1 / 2}} \exp \left(\frac{1}{2}\left(\bar{a}-\bar{m}_{i j}\right)^{\prime} \Sigma_{i j}^{-1}\left(\bar{a}-\bar{m}_{i j}\right)\right)
$$

where $\Sigma_{i j}$ is the estimator of the covariance matrix. 
Let the set $M_{i j}$ be of the form: $M_{i j}=\left\{\bar{a}_{1}, \bar{a}_{2}, \ldots, \bar{a}_{n}\right\}$.Thus, for the estimation of the covariance matrix we use the following estimator:

$$
\Sigma_{i j}=\frac{1}{n-1} \sum_{l=1}^{n}\left(\bar{a}_{l}-\bar{m}_{i j}\right)\left(\bar{a}_{l}-\bar{m}_{i j}\right)^{\prime} .
$$

\section{- Step 5 .}

When the distributions for all $k$ clusters are built they are fused to form the final characteristics of the indifference set considered given by the formula:

$$
f_{R S_{l}}(\bar{a})=\frac{1}{k} \sum_{j=1}^{k} f_{M_{i j}}(\bar{a})
$$

\section{- Step 6.}

Steps 1 to 5 are repeated for all $R S_{i}$ where $i=1, \ldots, n$.

The sequence of probability distributions assigned to the surfaces together with the utility values form a basis for the negotiation offers scoring system:

$$
\left(f_{R S_{i}}, u_{i}\right): i=1, \ldots, n
$$

\subsubsection{The Computation of an Offer's Scoring}

When the negotiator starts the actual negotiation phase they can evaluate any alternative that occurs within the negotiation process. If the negotiator is interested in the final scoring of a new alternative $\bar{a}$ the NegoManage decision support unit performs the scoring check using the scoring system (19). The alternative's score is computed in the form of von Neumann-Morgenstern expected utility (von Neumann and Morgenstern 1944). We use this concept because for each indifference surface we can obtain a probability value describing the alternative degree of belonging to a particular surface

$$
p(i)=p_{i}(\bar{a})=f_{R S_{i}}(\bar{a}): i=1, \ldots, n .
$$

Therefore, the system computes the degree of belonging to all indifference surfaces and fuses it with utility values assigned to all surfaces. The sum of the products of utility values with probability levels gives the final scoring of the new alternative:

$$
S(\bar{a})=\sum_{i=1}^{n} p_{i}(\bar{a}) \cdot u_{i}
$$

\subsection{The Preference Consistency Check}

As in some MCDM methods the issue of preference consistency occurs also in our NegoManage approach. We will say that the preferences are consistent if there is no overlap between indifference surfaces. This postulate results from the fact that if 
one alternative belongs to an indifference surface with a particular level of utility it should not belong to an indifference surface with different value of utility. The level of overlap of two indifference surfaces is an indicator of preferences consistency. This value can be computed using Jaccard coefficient since this measure indicates the level of similarity of two sets. In the case of crisp sets the surfaces should be completely disjoint to preserve the consistency of the preferences. However, if there is a partial overlap between the surfaces the Jaccard index indicates the extent to which the consistency is violated. The Jaccard index is given by the formula:

$$
J(A, B)=\frac{|A \cap B|}{|A \cup B|} .
$$

In the NegoManage system we have at our disposal a surface characteristics given in the form of probability distribution. Such a distribution assigns to each alternative a probability of belonging to the indifference surface. The Jaccard index may operate on fuzzy sets but, unfortunately, we have at our disposal probability distributions only, not membership functions. However, based on the rationale in Dubois et al. (2004) we may convert probability distributions of any two indifference sets denoted as $f_{R S_{i}}, f_{R S_{j}}$ into the corresponding possibility distributions $\pi_{R S_{i}}, \pi_{R S_{j}}$. We obtain thus:

$$
J\left(R S_{i}, R S_{j}\right)=\frac{\left|R S_{i} \cap R S_{j}\right|}{\left|R S_{i} \cup R S_{j}\right|}=\frac{\max _{\bar{u} \in \Omega} \min \left(\pi_{R S_{i}}(\bar{u}), \pi_{R S_{j}}(\bar{u})\right)}{\max _{\bar{u} \in \Omega} \max \left(\pi_{R S_{i}}(\bar{u}), \pi_{R S_{j}}(\bar{u})\right)} .
$$

The consistency check is based on the rule that the more distant two surfaces are, the lower should be the value of the Jaccard coefficient (the level of overlap).

\section{Negotiator Profiling and Reputation System}

\subsection{Formal Approach for Identifying Negotiators' Profiles}

One of the key problems in electronic negotiations is the lack of knowledge of the counterpart, since the partner is neither seen nor heard. When the actual negotiation phase starts the partner is entirely anonymous which can result in a feeling of discomfort for the negotiator. To overcome the problem of total anonymity NegoManage introduces the concept of negotiator profiling. The negotiators' profiles can be created in various ways. Our profile creation mechanism involves the evaluation of a negotiator in terms of their negotiation style. One of the approaches to deriving the description of negotiation style is the Thomas-Kilmann (TKI) questionnaire (Kilmann and Thomas 1983). This tool aims at evaluating the negotiator by asking a series of questions regarding the reaction types in different conflict situations. Based on the questionnaire the negotiator's style is determined in terms of five possible behaviors, including: Competing, Collaborating, Avoiding, Accommodating and Compromising. These behaviors correspond to two major features of negotiator, namely: cooperativeness and assertiveness, since according to Thomas and Killman each of the five behavior types may be described by indicating a rough level of these two features (see Fig. 3). 
Fig. 3 Thomas-Kilmann conflict modes

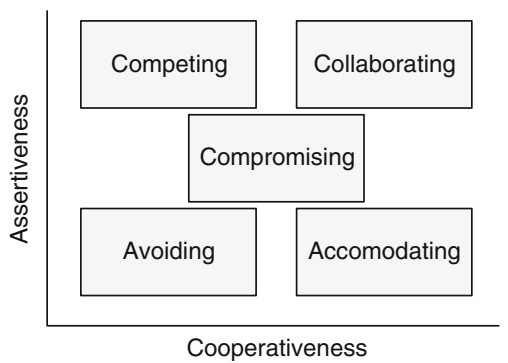

In NegoManage we use a different mechanism for measuring the degrees of cooperativeness and assertiveness. The profiling is done by analyzing the messages exchanged and classified by the negotiators based on the negotiation context speech act taxonomy (Brzostowski and Wachowicz 2010). This approach is based on the assumption that the profile of the negotiator influences their negotiation behavior, i.e. the offers they exchange and the messages they formulate (see Kersten and Wu 2010; Wachowicz and Wu 2010). However, the mechanisms of calculating the profile elements (descriptive characteristics) is similar to the one applied in TKI. The one difference is that instead of asking the negotiator about some particular patterns of their behavior (as in TKI) we ask them to evaluate their true behavior they present in the form of argumentation included in the messages they exchange during the negotiation process.

There are also other speech act taxonomies, e.g. the one proposed by Searle (1969) and Stiles (1992) that give some insight into speech act theory. However, these taxonomies do not take into consideration the issues that are important from the viewpoint of negotiation context such as the distinction between forward and backward communication functions. Similarly, as in DAMSL annotation scheme (Core and Allen 1997), our taxonomy splits the speech act types into forward and backward communicative functions. This division is crucial in the negotiation context since the negotiation discourse is a process of exchanging messages with different messages constituting different types of requests, and different types of responses to requests.

Thus in NCSAT, if the atomic speech act contained in a message is a form of request, the negotiator's cooperativeness is increased if the response to this message is positive, e.g. the responding message satisfies the request. If the response to a request is negative, the cooperativeness degree decreases. In the case of assertiveness feature, the situation is analogous except that the message's sender is assessed. If the sender receives a positive response to their request, their assertiveness increases, if negative-their assertiveness decreases. Each single speech act contributes to the update of the assertiveness level of one party and the cooperativeness level of the other party. However, these concepts are not complementary since the values are aggregated over multiple negotiation threads in multiple negotiation processes the negotiator takes part in. This principle is based on our former postulate that communication leading to positive results means that the sender is assertive (Brzostowski and Wachowicz 2010). The speech act taxonomy used in NegoManage is presented in Table 1.

Let $\bar{a}_{i, j}^{\alpha \rightarrow \beta}=\bar{a}^{\alpha \rightarrow \beta}(i, j)$ be an atomic speech act uttered by the negotiator $\alpha$ to the negotiator $\beta$. The number $i$ denotes the index of the message in the whole 
Table 1 The negotiation context speech act taxonomy

\begin{tabular}{|c|c|c|c|}
\hline $\begin{array}{l}\text { Direction of a } \\
\text { speech act }\end{array}$ & $\begin{array}{l}\text { Intention } \\
\text { of a speech act }\end{array}$ & $\begin{array}{l}\text { The issue } \\
\text { of discourse }\end{array}$ & Description \\
\hline \multirow[t]{5}{*}{$\begin{array}{l}\text { Forward } \\
\text { communicative } \\
\text { function }\end{array}$} & \multirow[t]{2}{*}{$\begin{array}{l}\text { Inform } \\
\text { interlocutor }\end{array}$} & Perform action & $\begin{array}{l}\text { IPA Informing the partner about performing } \\
\text { an action or intending to perform an } \\
\text { action }\end{array}$ \\
\hline & & Give information & $\begin{array}{l}\text { IGI Informing the partner about facts or } \\
\text { beliefs without intention to discuss it }\end{array}$ \\
\hline & \multirow[t]{3}{*}{$\begin{array}{l}\text { Request from } \\
\text { interlocutor }\end{array}$} & Perform action & $\begin{array}{l}\text { RPA Requesting the partner to perform an } \\
\text { action }\end{array}$ \\
\hline & & Give information & $\begin{array}{l}\text { RGI Requesting the parnter to give } \\
\text { information (Asking question) }\end{array}$ \\
\hline & & Accept belief & $\begin{array}{l}\text { RAB Requesting the partner to accept the } \\
\text { stated belief }\end{array}$ \\
\hline $\begin{array}{l}\text { Direction of a } \\
\text { speech act }\end{array}$ & $\begin{array}{l}\text { Intention of a } \\
\text { speech act }\end{array}$ & $\begin{array}{l}\text { The type of } \\
\text { response }\end{array}$ & Description \\
\hline \multirow{13}{*}{$\begin{array}{l}\text { Forward } \\
\text { communicative } \\
\text { function }\end{array}$} & \multirow[t]{3}{*}{ Respond to IPA } & Positive & $\begin{array}{l}\text { Thanking the partner for performed } \\
\text { action }\end{array}$ \\
\hline & & Negative & $\begin{array}{l}\text { Disapproving the action performed by the } \\
\text { partner }\end{array}$ \\
\hline & & $\begin{array}{l}\text { Not understood } \\
\text { Ignored }\end{array}$ & $\begin{array}{l}\text { Signaling not understanding the speech act } \\
\text { No responding signal }\end{array}$ \\
\hline & Respond to IGI & $\begin{array}{l}\text { Positive } \\
\text { Negative } \\
\text { Not understood } \\
\text { Ignored }\end{array}$ & $\begin{array}{l}\text { Thanking the partner for given information } \\
\text { Disapproving the information revelation } \\
\text { Signaling not understanding the speech act } \\
\text { No responding signal given }\end{array}$ \\
\hline & \multirow[t]{3}{*}{ Respond to RPA } & Positive & $\begin{array}{l}\text { Informing about performing the requested } \\
\text { action }\end{array}$ \\
\hline & & Negative & Refusing to perform the requested action \\
\hline & & $\begin{array}{l}\text { Not understood } \\
\text { Ignored }\end{array}$ & $\begin{array}{l}\text { Signaling not understanding the speech act } \\
\text { No responding signal given }\end{array}$ \\
\hline & \multirow[t]{3}{*}{ Respond to RGI } & Positive & Revealing the requested information \\
\hline & & Negative & Refusing to reveal the requested information \\
\hline & & $\begin{array}{l}\text { Not understood } \\
\text { Ignored }\end{array}$ & $\begin{array}{l}\text { Signaling not understanding the speech act } \\
\text { No responding signal given }\end{array}$ \\
\hline & \multirow[t]{3}{*}{ Respond to RAB } & Positive & $\begin{array}{l}\text { Accept the statement presented in the speech } \\
\text { act }\end{array}$ \\
\hline & & Negative & $\begin{array}{l}\text { Deny the statement and/or give } \\
\text { counterargument }\end{array}$ \\
\hline & & $\begin{array}{l}\text { Not understood } \\
\text { Ignored }\end{array}$ & $\begin{array}{l}\text { Signaling not understanding the speech act } \\
\text { No responding signal given }\end{array}$ \\
\hline
\end{tabular}

Source Brzostowski and Wachowicz (2010)

communication thread, while $j$ denotes the index of the speech act contained in the message. In NegoManage, each atomic speech act is encoded in the following way

$$
\bar{a}_{i, j}^{\alpha \rightarrow \beta}=\left(n_{i, j}, t_{i, j}, d_{i, j}, \bar{r}_{i, j}\right)
$$

where,

$-n_{i, j}$ is the intention of the speech act $\left(n_{i, j} \in\{1, \ldots, 7\}\right.$, see Table 1$)$, 
$-t_{i, j}$ is either the issue of discourse or the type of speech act depending on the intention of the speech act $\left(t_{i, j} \in\{1, \ldots, 4\}\right.$, according to Table 1 there are either 2 possible issues of discourse for the first type of intention and 3 possible issues of discourse for the second type of intention or 4 possible types of response in the case of five remaining types of intentions),

$-d_{i, j}$ is the degree of importance specified by the sender of speech or the degree of response importance specified by the receiver (the value of $d$ can be specified on a finite point scale, for instance $\left.d_{i, j} \in\{1, \ldots, 7\}\right)$.

$-\bar{r}_{i, j}$ identifies the forward communicative function speech act to which the current $\bar{a}_{i, j}^{\alpha \rightarrow \beta}$ speech act is responding. For all forward communicative function speech acts the value of $\bar{r}_{i, j}$ is simply coded as $(0,0)$.

For each pair of speech acts in the form of request $\left(\bar{a}_{i, j}^{\alpha \rightarrow \beta}\right)$ and response to this request $\left(\bar{a}_{k, l}^{\beta \rightarrow \alpha}\right)$, the cooperativeness/assertiveness coefficient of the negotiators is computed as follows. For the positive response a product of request importance degree $\left(d_{i, j}\right)$ and response importance degree given in the response $\left(d_{k, l}\right)$ are multiplied and added to the overall scoring. As a result of this operation the cooperativeness degree of the negotiator $\alpha$ increases. In the case of negative response the product of request importance degree and response importance degree are subtracted from the overall scoring of cooperativeness degree.

Formally, the cooperativeness/assertiveness coefficient is determined as follows:

$$
\operatorname{deg}_{\text {assertiveness }}^{\alpha}=\operatorname{deg}_{\text {cooperativeness }}^{\beta}=m\left(t_{k, l}\right) \times d_{i, j} \times d_{k, l},
$$

where $m$ is a multiplier whose value depends on the type of response the speech act recipient (negotiator $\beta$ ) is giving to its emitter (negotiator $\alpha$ ), and $m \in\langle-1 ; 1\rangle$ (positive value in the case of positive response, negative value in the case of negative response or 0 in the case of neutral response).

For the assertiveness feature the operation is analogous except that in the case of cooperativeness it is computed for the responding negotiator, and in the case of assertiveness it is computed for the requesting negotiator. During the process of message evaluation, the negotiator specifies the message parameters by indicating the degree of importance of a message and in the case of incoming message he/she specifies if it's a positive, negative or neutral response. Such an evaluation may seem quite subjective but a more objective method of evaluation requires to automate the evaluation process by a central unit independent of the negotiators, which is a part of future work. The current software solution requires the user to split the message into parts corresponding to the particular speech acts and utter them separately.

\section{Post-negotiation Improvements of the Negotiated Compromise}

\subsection{Formal Model of Identifying the Bargaining Solution in Negotiations}

The negotiation parties do not know the preferences of their counterparts, therefore the negotiation compromise they finally achieve (if any) may be far from the efficient 
frontier. In order to reach a Pareto efficient outcome the structure of preferences of both parties has to be taken into account and the negotiation symmetric analysis should be conducted (see Raiffa 1982). We employ the concept of bargaining solution to improve (in terms of Pareto efficiency) the outcome obtained in the actual negotiation phase (Brzostowski 2012). To perform this task we use the Gupta-Livne bargaining solution (Gupta and Livne 1988), whose rationale is convincing and may be relatively easily implemented when the negotiators use the scoring systems we proposed. The general idea of this improvement is the following:

- In the first stage of the post-optimization the preferences are aggregated to compute the Pareto efficient frontier in the space of utility profiles of both parties.

- Then the reference point, which corresponds to the negotiation outcome, is connected with the utopia point in the space of utility profiles.

- The intersection of the Pareto frontier with the line connecting reference with utopia is determined. This profile of utilities, each reflecting one party's performance, corresponds to an alternative considered to be the improved solution.

Formally, the improvement procedure has the following form:

- Let us assume that we consider $m$ issues during the negotiation process, where $\left[a_{i}, b_{i}\right]$ is the range of the $i$ th issue. Since the scoring system is not given in explicitly, we have to select representative points from the continuous space of alternatives, for which the score values can be computed. Such score values represent an approximation of the preference structure.

- First we consider the space of feasible solutions as the Cartesian product of ranges corresponding to all issues considered:

$$
D=\left[a_{1}, b_{1}\right] \times\left[a_{2}, b_{2}\right] \times \cdots \times\left[a_{m}, b_{m}\right] .
$$

- Next, the set $D$ is discretized, namely for each issue we choose $n$ discrete options equally distributed in the range of every issue:

$$
\left\{c_{1}^{k_{1}} \mid k_{1} \in\{1, \ldots, n\}\right\} \in\left[a_{i}, b_{i}\right] .
$$

As a result of discretization the set $D$ is substituted by the following set:

$$
\begin{aligned}
S= & \left\{c_{1}^{k_{1}} \mid k_{1} \in\{1, \ldots, n\}\right\} \times\left\{c_{2}^{k_{2}} \mid k_{2} \in\{1, \ldots, n\}\right\} \times \cdots \\
& \times\left\{c_{m}^{k_{m}} \mid k_{m} \in\{1, \ldots, n\}\right\} \subset D
\end{aligned}
$$

which may be rewritten as

$$
S=\left\{\left(c_{1}^{k_{1}}, c_{2}^{k_{2}}, \ldots, c_{m}^{k_{m}}\right) \mid k_{1}, k_{2}, \ldots, k_{m} \in\{1, \ldots, m\}\right\} \subset D
$$

- In the next stage the payoff profiles (profiles of scores) of both parties have to be computed for the discrete points of the set $S\left(c_{1}^{k_{1}}, c_{2}^{k_{2}}, \ldots, c_{m}^{k_{m}}\right)$. We use the scoring systems of both negotiating parties (see Sect. 2.3): 


$$
\begin{aligned}
v_{1}\left(c_{1}^{k_{1}}, c_{2}^{k_{2}}, \ldots, c_{m}^{k_{m}}\right) & =v_{k_{1} k_{2}, \ldots, k_{m}}^{1}, \\
v_{2}\left(c_{1}^{k_{1}}, c_{2}^{k_{2}}, \ldots, c_{m}^{k_{m}}\right) & =v_{k_{1} k_{2}, \ldots, k_{m}}^{2}
\end{aligned}
$$

where $v_{1}$ and $v_{2}$ are the value functions of both parties (1 and 2). From this we obtain the set of score profiles of both parties in the following form:

$$
\begin{aligned}
V & =\left\{\left(v_{k_{1} k_{2} \cdots k_{m}}^{1}, v_{k_{1} k_{2} \cdots k_{m}}^{2}\right) \mid k_{1}, k_{2}, \ldots, k_{m} \in\{1, \ldots, n\}\right\} \\
& =\left\{\left(v_{l}^{1}, v_{l}^{2}\right) \mid l \in\left\{1, \ldots, n^{m}\right\}\right\} .
\end{aligned}
$$

In this formula multiple indices of scores have been substituted by one index.

- Then we have to determine the Pareto frontier of the set $V$. The points of the Pareto front $P$ are of the following form:

$$
\begin{aligned}
P & =\left\{\left(v^{1}, v^{2}\right) \in V \mid\left(w^{1}, w^{2}\right) \in V \wedge\left(w^{1}, w^{2}\right) \neq\left(v^{1}, v^{2}\right)\right. \\
& \left.\Rightarrow \neg\left(w^{1}, w^{2}\right) \succ\left(v^{1}, v^{2}\right)\right\} .
\end{aligned}
$$

As we can see these are all the points which are not dominated by other points in the set $V$.

- Assuming now that we have at our disposal the reference alternative mapped into the space of utility profiles $\left(v_{r}^{1}, v_{r}^{2}\right)$ and the alternative corresponding to utopia $\left(v_{u}^{1}, v_{u}^{2}\right)$, we connect these two points in the space of score profiles as follows:

$$
R=\left\{\left(x_{1}, x_{2}\right):\left(x_{1}, x_{2}\right)=\left(v_{r}^{1}, v_{r}^{2}\right)+t \cdot\left(\left[v_{u}^{1}, v_{u}^{2}\right]-\left[v_{r}^{1}, v_{r}^{2}\right]\right) \mid t \in[0,1]\right\},
$$

and obtain the set $R$ of points connecting the two alternatives.

- The agreement improvement is determined as the alternative from $P$ nearest to the line connecting reference with utopia:

$$
p=\left(v_{i}^{1}, v_{i}^{2}\right) \in P \mid d\left(\left(v_{i}^{1}, v_{i}^{2}\right), R\right)=d(P, R) .
$$

meaning that $p$ is the point from $P$ nearest to the connection line.

The algorithm for improving the negotiation compromise described above is currently being implemented in the NegoManage system. Since it requires strategic and confidential information about the preferences (the scoring systems) of both parties the additional protocol of gathering the information about the parties' structures of preferences was developed, which assures they will not be revealed to the counterpart. 


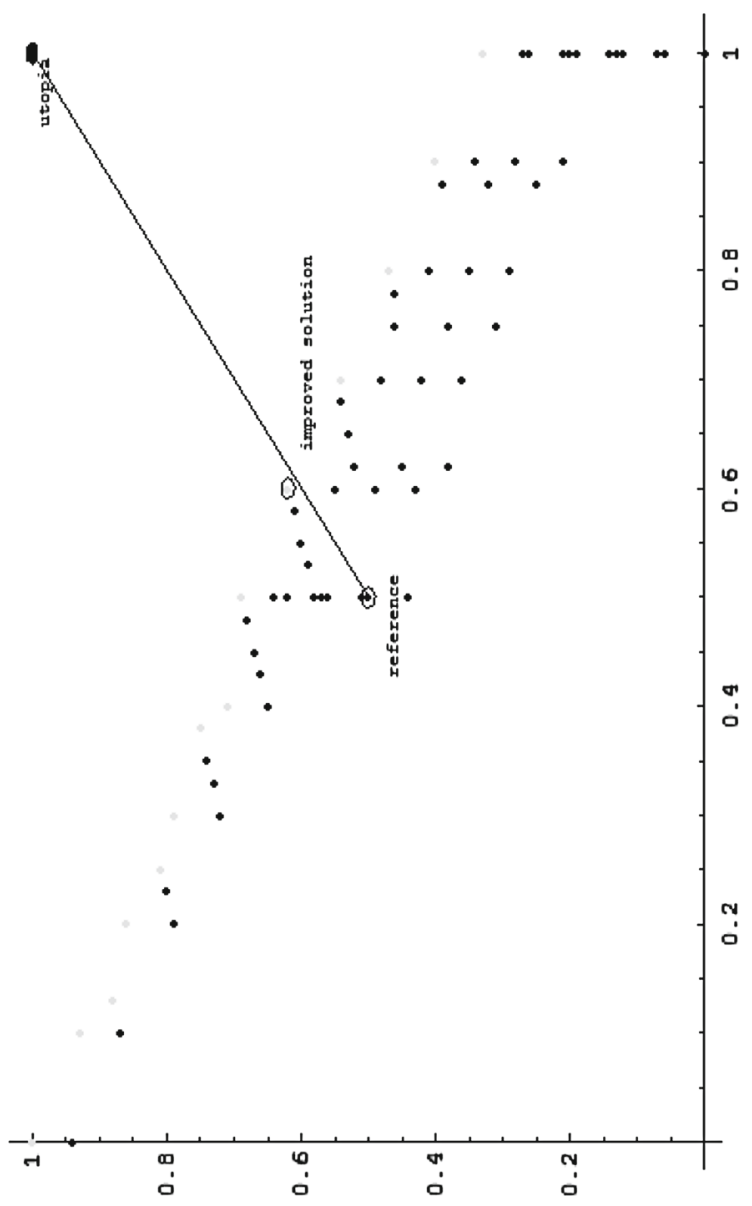

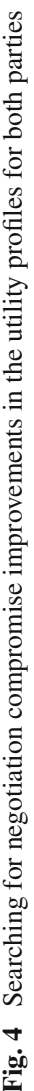




\section{NegoManage: The Negotiation Support System}

\subsection{System Configuration}

In this section we present NegoManage as a software system that implements the formal models introduced in the previous three sections. From the technical point of view the NSS may be designed and implemented in many different ways. Its architecture and configuration depend on the type of negotiation, its role in negotiations and the scope of their support (Stroebel 2003; Kersten and Lai 2007). The NegoManage system was designed as a distributed system that consists of:

- a set of units deployed on the Web that use public and private data to provide the negotiators with individual (asymmetric) and mutual (symmetric) advice and communication tools, and

- individual units for the satellite negotiators installed on the users' desktop computers, that are responsible for performing asymmetric decision analysis for the supported negotiators (see Brzostowski and Wachowicz 2009).

In this configuration there is a central Communication Unit $(\mathrm{CU})$ that plays the role of a communication center allowing the negotiating parties to exchange offers and messages. It also collects the data on the negotiation processes and the negotiators themselves, analyzes and presents them to the negotiators, providing them with the additional information that may be helpful within the actual negotiation process (e.g. visualizes the negotiation progress, depicts the concessions graphs, etc.). CU is connected to:

- the Post-Negotiation Optimization Unit (PNOU), which implements the model described in Sect. 5 is responsible for the analysis of the negotiation compromise and suggests possible improvements, and

- the dedicated Reputation System (RS), used for the negotiators' profiles analysis. CU presents to the users the negotiation profile information about all registered negotiators, which allows negotiator to choose the best counterpart for the forthcoming negotiation, reduces the negotiation anonymity and allows the negotiators to better prepare the pre-negotiation phase (i.e. to adjust the negotiation strategy to the individual characteristics of the potential counterpart).

Communication Unit is not dependent on any of the negotiators but it can be controlled by a third party as a mediator or arbitrator or it can be used for symmetric support of the negotiators in search of mutually satisfying compromises.

The NegoManage's Decision Support Units (DSU) are the decision analysis engines installed on the desktop computers of negotiators. They are used by negotiators in the pre-negotiation phase to elicit their individual preferences and in actual negotiation phase to evaluate incoming offers.

The NegoManage general configuration scheme is shown in Fig. 5.

Such a configuration of the system allows to keep all the sensitive and strategic data (e.g. preferences) solely on the personal computers of the negotiation participants assuring it will not be transferred or revealed to their counterparts. Simultaneously, the system uses the DSUs to perform all the complicated and time consuming calculations, 


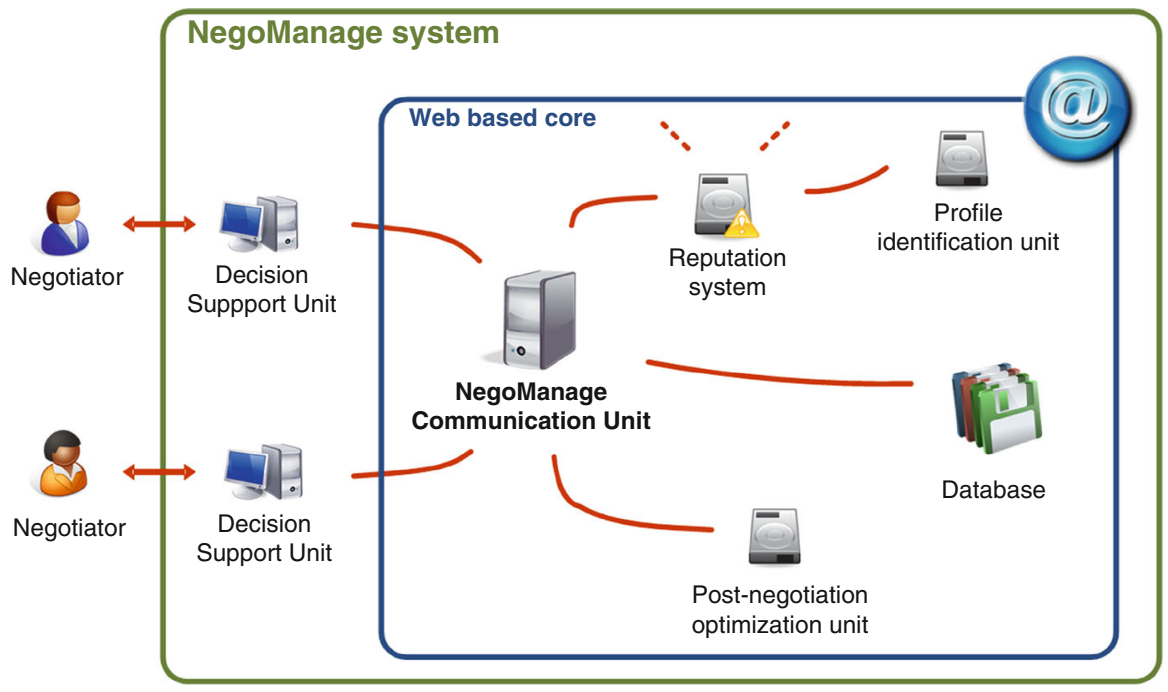

Fig. 5 NegoManage major components

thus the $\mathrm{CU}$ is released from the computational tasks and devoted to communication support and data visualization only.

\subsection{Decision Support Unit}

The Decision Support Unit helps to structure the negotiation problem and elicit negotiator's preferences by implementing the formal solutions described in Sect. 2. It was designed in the form of preference creator and consists of the following steps:

- Step 1. Calibration of the linguistic utility scale

When specifying the scores for indifference surfaces, a NegoManage user operates on a numeric scale formed from two 7-level scales which are integrated together hierarchically (Brzostowski and Wachowicz 2011). The scale has to be calibrated before use. The calibration process involves the assignment of numeric scores to their verbal equivalents. According to research by Moshkovich et al. (2005) the decision-maker can cope with a linguistic scale consisting of 7 levels only. However, in our particular application context the 7-level scale does not provide a sufficient resolution level since the precision of evaluation is too low. By using two integrated 7-level scales we aim at a compromise between the intuitiveness of evaluation and its precision. By selecting a level from the first scale the user can specify an approximate level of evaluation assigned to the surfaces. By selecting a level from the second scale the user specifies the score more precisely since this value is located between the two consecutive levels of the first scale. This approach allows to increase the precision of evaluation without giving up the intuitive 7-levels scale (see Fig. 6).

- Step 2. Definition of the negotiation space 


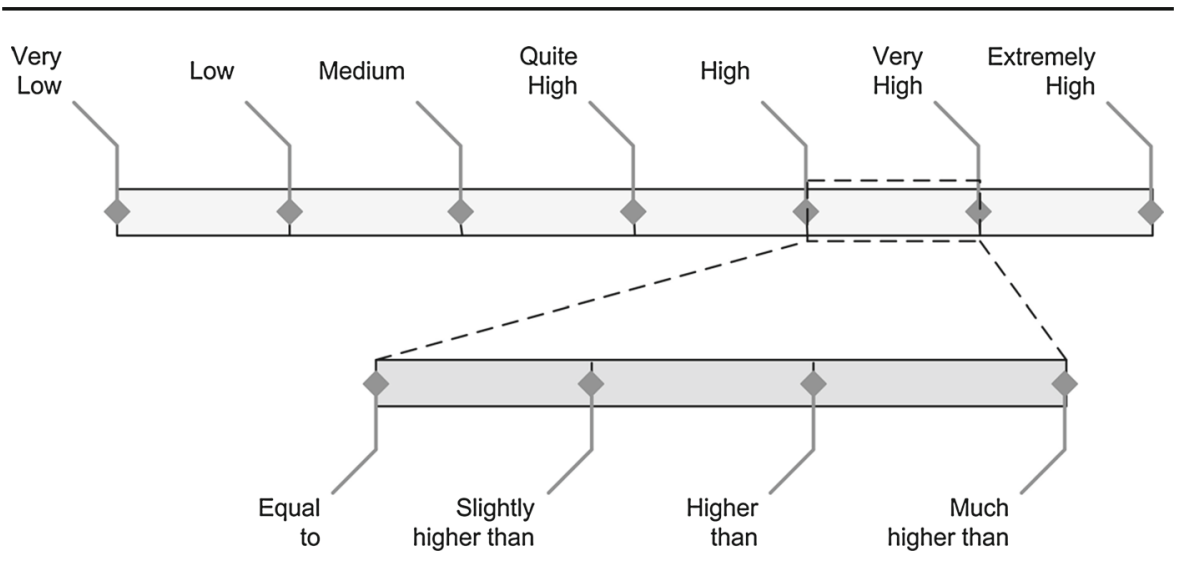

Fig. 6 Integrated 7-level linguistic scale

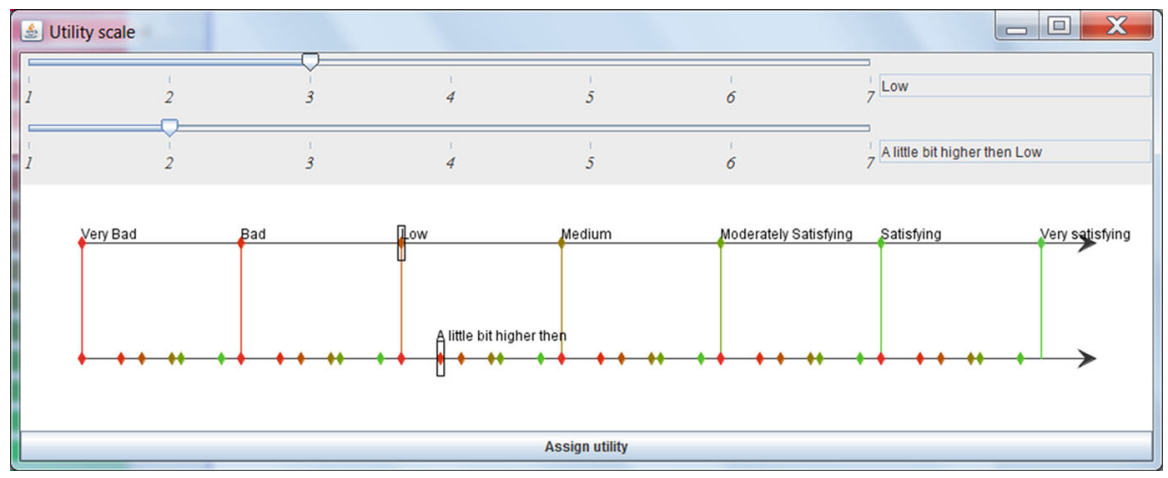

Fig. 7 The illustration of double, integrated, hierarchical scale for the assessment of an indifference surface

In this step the negotiators define the negotiation issues and specify the corresponding ranges of resolution levels for all negotiation issues. The issues are assumed to have quantitative characteristics. Moreover, the negotiators specify the number of indifference surface that will be defined in the next stages of analysis.

After defining the problem structure and calibrating the utility scale the negotiators can start to define their structure of preferences over the set of feasible alternatives determined in the problem definition step.

- Step 3. Evaluation of the indifference surfaces

Each surface has to be assigned a level of linguistic utility selected from the double integrated, calibrated verbal utility scale. Using a slider-based surfaces evaluator the negotiator describes the quality of each identified surface. An example of surface utility definition is given in Fig. 7.

- Step 4. Identification of the surface representatives

The negotiators prepare reference alternatives in the form of complete packages classified into indifference surfaces. The reference alternatives have to be fully defined in terms of full packages. In Fig. 8 we presents the main form of the 


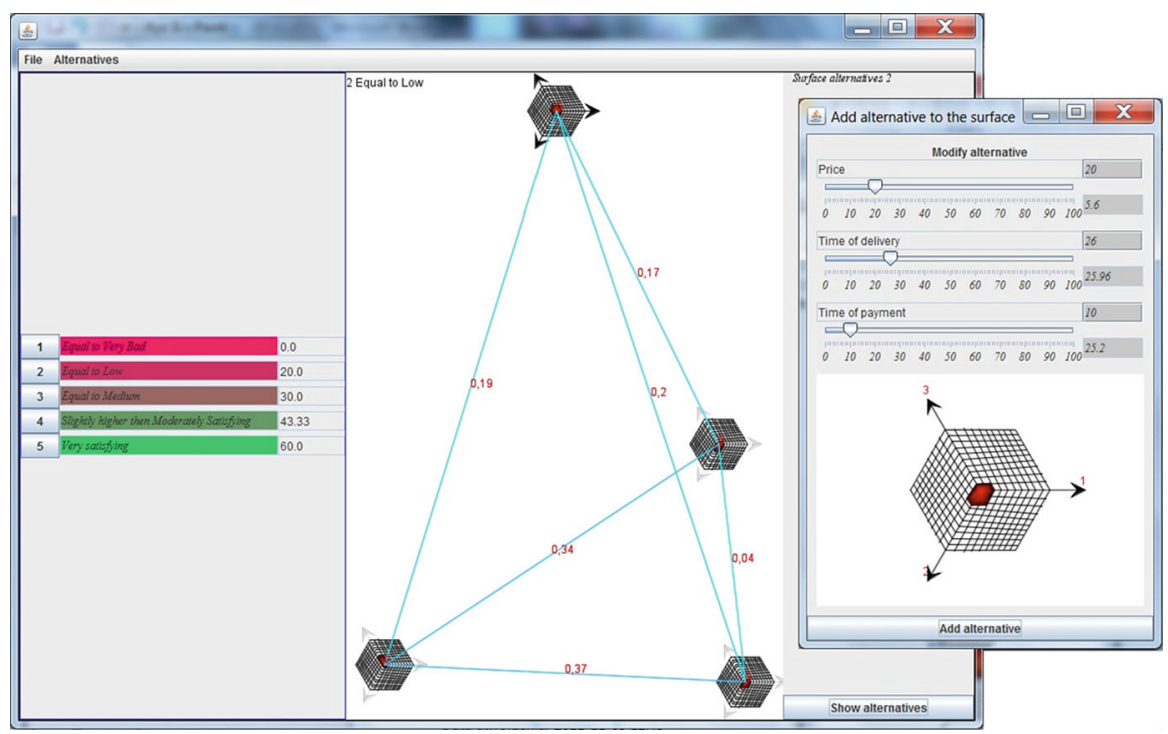

Fig. 8 The illustration of preference analysis by means of offer examples assignment

preference analysis module. In the left part of the form the linguistic and numeric scores of the consecutive indifference surfaces are displayed. In the middle, the selected surface is displayed with all the alternatives constituting this surface. To display the alternatives on a plane the system performs multi-dimensional scaling, since the alternatives are multi-dimensional objects, and when mapped onto a plane the distances between alternatives must be retained. The system copes with alternatives in three, four and five dimensions. The smaller form at the right displays the alternative under consideration. The user can set the values of issues by manipulating sliders corresponding to consecutive issues. The alternative under evaluation is visualized using its projections onto two-dimensional subspaces of the space of alternatives. Each parallelogram separated by two axes corresponds to a quarter of the plane, and each axis corresponds to one issue.

\subsection{Communication Unit}

The Communication Unit is a central part of NegoManage system that coordinates the negotiators' activities, allows for an exchange of offers and messages, visualizes the negotiation progress and is an interface for the profiling unit (which is a part of the reputation system). Each message that may be sent via CU contains an offer (the package definition) and a message explaining why this offer is proposed at the current stage of the negotiation process (the argumentation). While specifying an offer the negotiator inputs also his private scoring computed by his individual DSU. He inputs the offer to the message form, prepares the explaining message and formalizes its elements. If a message is treated as a request his specifies the level of importance of this request. If the message is a response to the previous request from their counterpart 


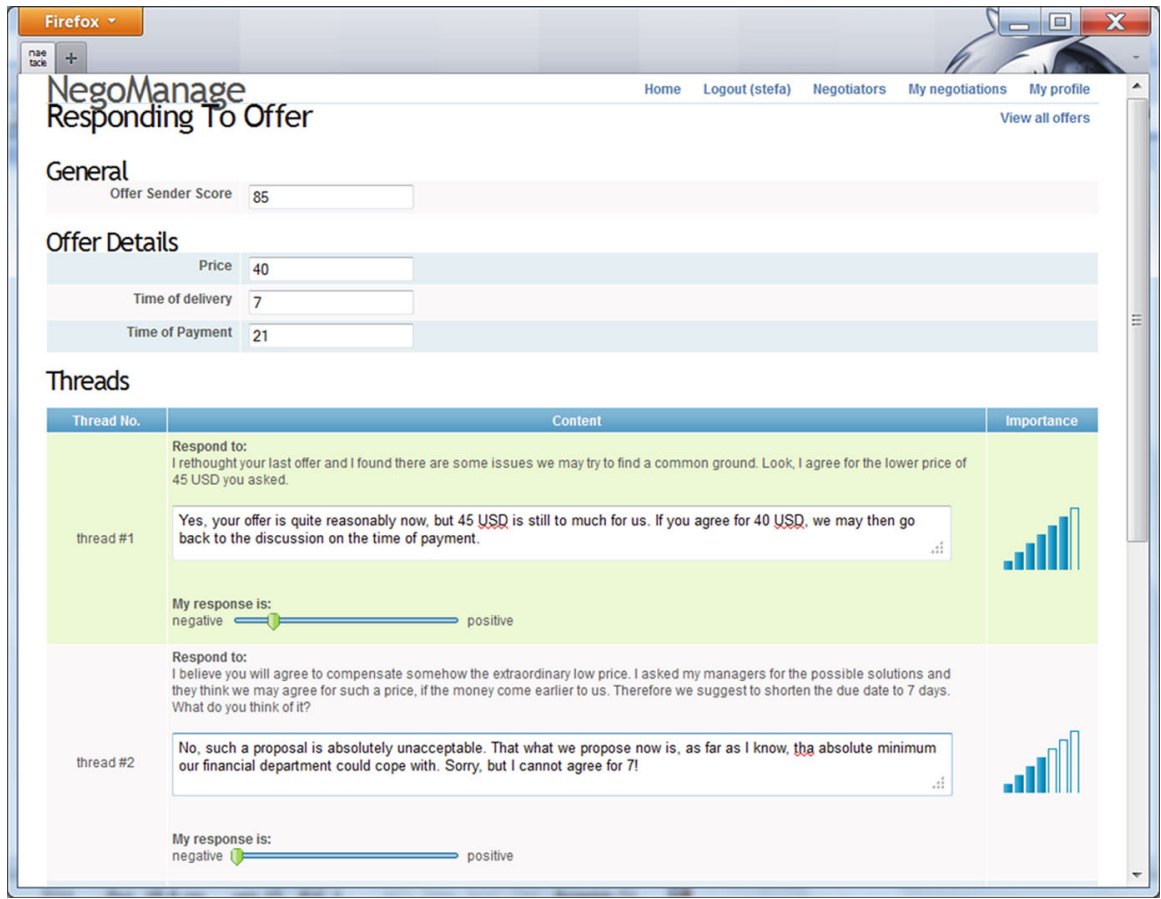

Fig. 9 Offers' construction in CU

the negotiator evaluates the subjective importance of the counterpart's request. These degrees are used in negotiator's profile construction by the Profile Identification Unit (see Sect. 3). The CU's interface used by the negotiator to specify his offer is shown in Fig. 9.

The series of offers and counteroffers is also visualized in the graph using private scoring assigned to the offers that occurred in the negotiation process. It allows to track the negotiation progress and the scales of the concessions in the successive negotiation rounds (see Fig. 10).

Within the CU the negotiators may also identify their own negotiation profiles by means of a TKI questionnaire. By using the data collected and processed by the reputation system, the $\mathrm{CU}$ presents also the actual negotiation profile of the supported negotiator, built on the basis of negotiation context speech act taxonomy (NCSAT) (Brzostowski and Wachowicz 2010). It may be confronted with the TKI results to analyze the negotiator's own bargaining style. The CU displays also a list of registered negotiators with the basic information on their profiles determined on the basis on NCSAT, which may help the focal negotiator to prepare an adequate negotiation strategy and the argumentation line that best fit their counterpart's potential behavior.

\section{Conclusions}

In this paper we described in detail the original negotiation support system called NegoManage. To show the major differences between NegoManage and other NSSs 


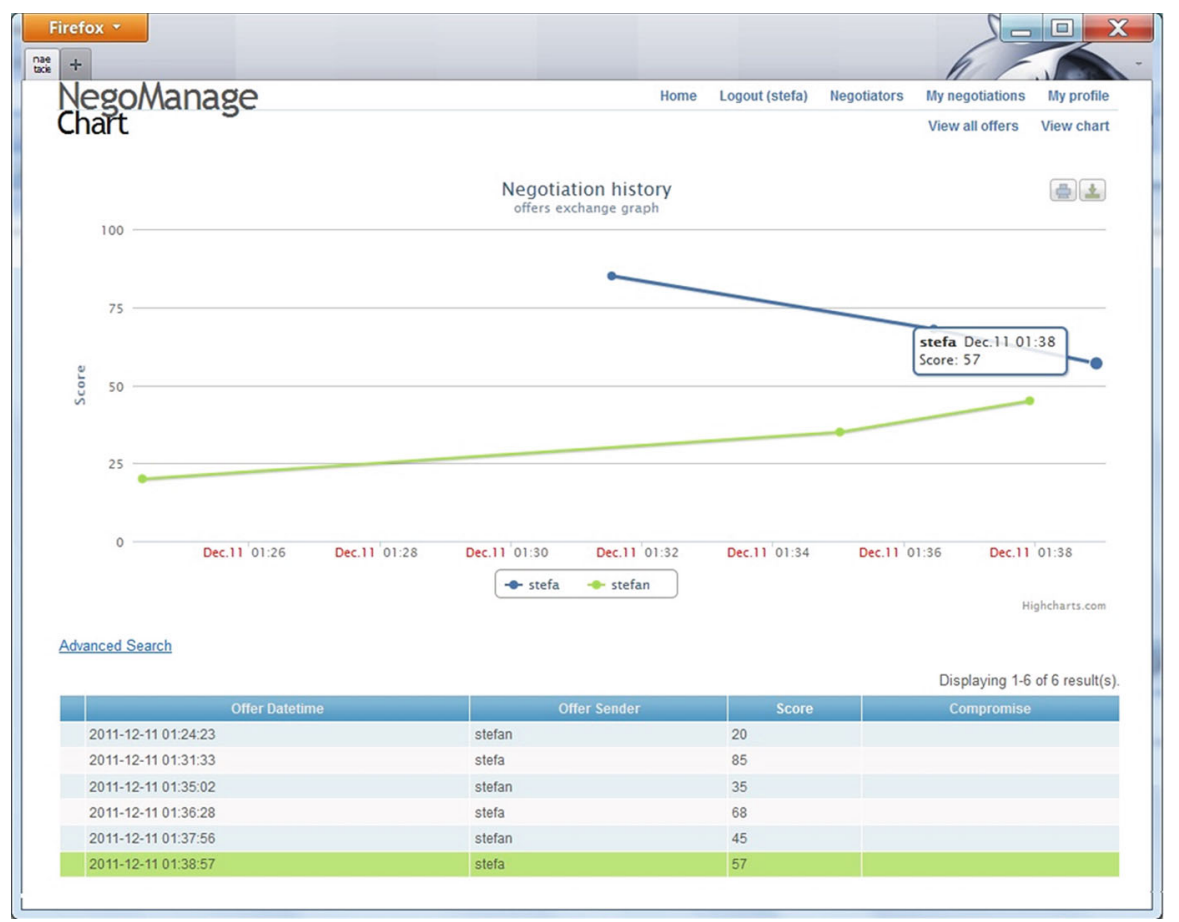

Fig. 10 CU's negotiation history graph and the offers history

currently available on the Web we have described three of its functionalities that are based on the original and novel algorithms: the preference analysis system, the profiling mechanism and the post-negotiation optimization algorithm, in terms of both the methodology used and its usage by human actors. These formal mechanisms are, in our opinion, an important contribution to the negotiation analysis, since they allow for supporting the negotiation preparation and conduct using an alternative approach that may eliminate some disadvantages of the methods traditionally applied in NSS (such as SAW or questionnaire-based scenarios).

The whole notion of analyzing preferences and building the scoring system that is applied in NegoManage differs significantly from the typical solutions applied in the well-known and frequently used in training and practice NSSs such as Inspire, Negoisst or SmartSettle. The solution we proposed does not require the negotiator to assign abstract scores to the issues and options or to weight the issues. Instead, the negotiator defines their preferences by means of verbal intuitive evaluation and defines the classes of offers of different quality, assigning simultaneously the examples of the offers to each of these classes. Then the computational algorithm is applied by the DSUs to build the scoring system adequately to the negotiators' preferences, that can be used later on to score any negotiation offer proposed in the actual negotiation phase.

The profiling mechanism allows to determine the negotiators' profiles in terms of two features: assertiveness and cooperativeness. It results in the negotiators' description similar to TKI, but does not require the parties to fill in the troublesome and time 
consuming questionnaire. The negotiators are only asked to subjectively evaluate the importance of each message, and depending on the type of their answers, the reputation system calculates the assertiveness/cooperativeness coefficients that are then incorporated in the overall profile description. The profiles we obtained describe the negotiators' true behavior in the negotiation process and do not rely on their subjective description of the hypothetical and theoretical situations that may never happen in the actual negotiation phase.

Finally, the post-negotiation optimization algorithm is responsible for determining the improvements of the negotiation compromises close to efficient frontier, which allows the negotiators to consume the whole negotiation pie not leaving any gains on the negotiation table. We have already conducted the preliminary tests on the use and usefulness of the system and the formal solutions applied. A small group of full-time students of mathematics and computer science took part in the negotiation experiments, during which they had an opportunity to learn each functionality of the NegoManage system. They also filled the post-negotiation questionnaires evaluating the system and suggesting potential improvements in the implemented software solutions. The conclusions are optimistic, however we need to take into account that this relatively small group of students had received good training and assistance during the negotiation activities, so any problem could have been immediately solved by the experiment supervisor. We plan to conduct a full test using a larger group of students pursuing various major subjects such as economics and management, who are usually not as skilled in mathematics and formal modeling as those participating in the preliminary tests. It will allow to answer the question on the level of acceptance of our tool among the average potential users of such a system.

Acknowledgments This research is supported by the grant from the Polish Ministry of Science and Higher Education (N N111 362337).

Open Access This article is distributed under the terms of the Creative Commons Attribution License which permits any use, distribution, and reproduction in any medium, provided the original author(s) and the source are credited.

\section{Appendix}

\subsection{An Example of Preference Analysis and Scoring System Construction}

For the sake of analysis illustration let us consider a simple negotiation problem. We assume that during the pre-negotiation talks the negotiators decided to deliberate over three issues, namely: price, warranty and delivery time. We will illustrate the process of preference analysis that is conducted in NegoManage on the basis of the formal model presented above from the buyer's point of view. The feasible ranges for the three issues considered have been specified as follows:

- Price: [\$20, \$80],

- Warranty: [2 months, 24 months],

- Delivery time: [7 days, 21 days]. 
Before starting the preference elicitation process we will use these data to prepare normalization formulas for resolution levels of issues. Normalization will protect us against miscalculations resulting from defining issue resolution levels on different scales. We will map the issues issue ranges into the $[0,1]$ interval using the standard normalization formula. For the price, the mapping is of the following form:

$$
g_{1}(\bar{a})=\frac{80-a_{p}}{80-20}=\frac{80-a_{p}}{60} .
$$

Analogously, the mappings corresponding to warranty and delivery time are of the following form:

$$
\begin{aligned}
& g_{2}(\bar{a})=\frac{a_{g}-2}{24-2}=\frac{a_{g}-2}{22}, \\
& g_{3}(\bar{a})=\frac{21-a_{d}}{21-7}=\frac{21-a_{d}}{14} .
\end{aligned}
$$

In the next stage of the analysis the negotiator defines indifference surfaces for different utility levels. Let the first three surfaces be defined as follows:

- $\mathbf{R S}_{1}=\{(0,0,0)\}$

- $\mathbf{R S}_{2}=\{(0.25,0.0,0.0),(0.0,0.25,0.0),(0.0,0.0,0.25)\}$

- $\mathbf{R S}_{3}=\{(0.0,0.0,0.5),(0.0,0.25,0.25),(0.25,0.00,0.25)$,

$$
(0.0,0.50,0.0),(0.25,0.25,0.0),(0.5,0.0,0.0)\}
$$

We will illustrate the computation of indifference surface probabilistic characteristic for the third indifference surface. If we denote each representative alternative fully belonging to the surface by $a_{i}$ (where $i$ is the alternative's index) these alternatives may be described as follows:

$$
\begin{aligned}
& a_{1}=(0.00,0.00,0.50), \\
& a_{2}=(0.00,0.25,0.25), \\
& a_{3}=(0.25,0.00,0.25), \\
& a_{4}=(0.00,0.50,0.00), \\
& a_{5}=(0.25,0.25,0.00), \\
& a_{6}=(0.50,0.00,0.00) .
\end{aligned}
$$

Now NegoManage performs the hierarchical clustering of this indifference surface. The initial partition consists of uni-elementary aggregates:

$$
P_{1}=\left\{\left\{a_{1}\right\},\left\{a_{2}\right\},\left\{a_{3}\right\},\left\{a_{4}\right\},\left\{a_{5}\right\},\left\{a_{6}\right\}\right\} .
$$

First, the distance matrix $D_{1}$ is computed to check which two agglomerations should be merged. Based on the clusters' means $m_{i}$ (centroids) the elements of the distance matrix are computed as follows:

$$
D_{1}(i, j)=d_{e}\left(m_{i}, m_{j}\right)
$$


where $d_{e}$ is the Euclidean distance. The matrix $D_{1}$ has the following form:

$$
D_{1}=\left[\begin{array}{llllll}
0 & 0.35 & 0.43 & 0.7 & 0.75 & 0.86 \\
0.35 & 0 & 0.25 & 0.35 & 0.43 & 0.61 \\
0.43 & 0.25 & 0 & 0.43 & 0.35 & 0.43 \\
0.7 & 0.35 & 0.43 & 0 & 0.25 & 0.5 \\
0.75 & 0.43 & 0.35 & 0.25 & 0 & 0.25 \\
0.86 & 0.61 & 0.43 & 0.5 & 0.25 & 0
\end{array}\right]
$$

The matrix elements $D_{1}(2,3)=0.25, D_{1}(4,5)=0.25$ and $D_{1}(5,6)=0.25$ are the smallest in $D_{1}$ (excluding the diagonal elements). Therefore, we have three possibilities of merging two clusters. We determine the within-group covariance matrix for each of the three possible merging options, and choose the option for which the matrix trace is minimal. The minimal trace is obtained for the elements $a_{2}$ and $a_{3}$ so they are grouped into joint agglomeration and we obtain:

$$
P_{2}=\left\{\left\{a_{1}\right\},\left\{a_{2}, a_{3}\right\},\left\{a_{4}\right\},\left\{a_{5}\right\},\left\{a_{6}\right\}\right\} \text {. }
$$

By continuing with the clustering algorithm we finally obtain the following sequence of ascending partitions:

$$
\begin{gathered}
P_{1}=\left\{\left\{a_{1}\right\},\left\{a_{2}\right\},\left\{a_{3}\right\},\left\{a_{4}\right\},\left\{a_{5}\right\},\left\{a_{6}\right\}\right\}, \\
P_{2}=\left\{\left\{a_{1}\right\},\left\{a_{2}, a_{3}\right\},\left\{a_{4}\right\},\left\{a_{5}\right\},\left\{a_{6}\right\}\right\}, \\
P_{3}=\left\{\left\{a_{1}\right\},\left\{a_{2}, a_{3}\right\},\left\{a_{4}, a_{5}\right\},\left\{a_{6}\right\}\right\}, \\
P_{4}=\left\{\left\{a_{1}\right\},\left\{a_{2}, a_{3}, a_{4}, a_{5}\right\},\left\{a_{6}\right\}\right\}, \\
P_{5}=\left\{\left\{a_{1}\right\},\left\{a_{2}, a_{3}, a_{4}, a_{5}, a_{6}\right\}\right\}, \\
P_{6}=\left\{\left\{a_{1}, a_{2}, a_{3}, a_{4}, a_{5}, a_{6}\right\}\right\} .
\end{gathered}
$$

with the successive fusion levels: 0.25 for $P_{1}$ and $P_{2}, 0.35$ for $P_{3}, 0.41$ for $P_{4}$ and 0.6 for $P_{5}$. If we assume that the fusion level is 0.5 we choose the partition $\mathrm{P}_{5}$ for further computation of multi-modal distribution. In this stage we have two clusters of the following form:

$$
\begin{gathered}
M_{1}=\left\{a_{1}\right\}, \\
M_{2}=\left\{\left\{a_{2}, a_{3}, a_{4}, a_{5}, a_{6}\right\}\right\},
\end{gathered}
$$

the means are computed for the clusters above:

$$
\begin{gathered}
m_{1}=a_{1}=(0.00,0.00,0.50) \\
m_{2}=0.2\left(a_{2}+a_{3}+a_{4}+a_{5}+a_{6}\right)=(0.2,0.1,0.1) .
\end{gathered}
$$


The covariance matrices for the two clusters are also computed:

$$
\begin{aligned}
\Sigma_{1}= & {\left[\begin{array}{lll}
0 & 0 & 0 \\
0 & 0 & 0 \\
0 & 0 & 0
\end{array}\right], } \\
\Sigma_{2}= & {\left[\begin{array}{ccc}
0.035 & -0.0075 & -0.0075 \\
-0.0075 & 0.015 & 0.015 \\
-0.0075 & 0.015 & 0.015
\end{array}\right] . }
\end{aligned}
$$

Since the first cluster is uni-elementary, the covariance matrix is singular at this stage. We add to the diagonal elements of the two matrices a small value that can be considered to correspond to the KDE bandwidth.

$$
\begin{aligned}
& \bar{\Sigma}_{1}=\Sigma_{1}+0.25 E, \\
& \bar{\Sigma}_{2}=\Sigma_{2}+0.25 E,
\end{aligned}
$$

where $E$ is the identity matrix.

In the next stage the obtained descriptions of clusters are used to form uni-modal bell-shaped distributions for both clusters:

$$
\begin{aligned}
& f_{M_{1}}(\bar{a})= 12.7389 \exp \\
&\left(\frac{1}{2}(\bar{a}-[0,0.5,0.5])^{\prime}\left[\begin{array}{lll}
0.025 & 0 & 0 \\
0 & 0.025 & 0 \\
0 & 0 & 0.025
\end{array}\right](\bar{a}-[0,0.5,0.5])\right), \\
& f_{M_{2}}(\bar{a})=6.46301 \exp \left(\frac{1}{2}(\bar{a}-[0.2,0.1,0.1])^{\prime}\right. \\
&\left.\times\left[\begin{array}{lll}
0.06 & -0.0075 & -0.075 \\
-0.075 & 0.04 & 0.015 \\
-0.0075 & 0.015 & 0.265
\end{array}\right](\bar{a}-[0.2,0.1,0.1])\right) .
\end{aligned}
$$

The final characteristic of the indifference surface $R S_{3}$ is represented by the following distribution:

$$
f_{R S_{3}}(\bar{a})=\frac{1}{2}\left(f_{M_{1}}(\bar{a})+f_{M_{2}}(\bar{a})\right) .
$$

The distributions for all the remaining surfaces are computed analogously.

\subsection{Sample Communication Thread and Reputation Profile Identification}

Let us analyze an example of calculation of the profile characteristics for a hypothetical communication thread in a bilateral negotiation. The history of offers and messages are presented in Tables 2, 3, and 4. 
Table 2 First message and offer (made by Eva)

\begin{tabular}{|c|c|c|}
\hline \multicolumn{2}{|l|}{ Contract } & \multirow[t]{2}{*}{ Message } \\
\hline Issue & Option & \\
\hline Price (USD): & 300,000 & Peter, \\
\hline Warranty (months): & 24 & $\begin{array}{l}\text { I am Eva and I represent the company Case in this negotiation. } \\
\text { After long deliberations we prepared an offer of buying the plane. } \\
\text { We think, it is a very good offer and we hope that you will } \\
\text { consider it for acceptable }\end{array}$ \\
\hline
\end{tabular}

Table 3 Second message and offer (made by Peter)

\begin{tabular}{|c|c|c|}
\hline \multicolumn{2}{|l|}{ Contract } & \multirow[t]{2}{*}{ Message } \\
\hline Issue & Option & \\
\hline Price (USD): & 320,000 & Dear Eva, \\
\hline Warranty (years): & 6 & $\begin{array}{l}\text { Thank you very much for your offer. Unfortunately the company } \\
\text { Rose can not accept this offer. However, we present a new offer } \\
\text { and hope that you will be able to accept it. Peter }\end{array}$ \\
\hline
\end{tabular}

Table 4 Third message (made by Eva)

\begin{tabular}{lll}
\hline Contract & & Message \\
\hline Issue & Option & \\
\hline Price (USD): & - & Peter, \\
Warranty (years): & - & This offer is acceptable \\
\hline
\end{tabular}

As we can see, the first message of Eva is a request to accept the negotiation offer by the partner (see Table 2). The encoded speech act is of the form:

$$
\bar{a}_{1,1}^{\alpha \rightarrow \beta}=(2,1,7,(0,0))
$$

The value 2 in the first position means that it is a request (see Table 1); the value 1 in the second position indicates that the issue of the discourse is "performing an activity" (in this situation: accepting an offer). Therefore, the first two values mean that the sender is requesting the receiver to perform activity. In the third position there is the level of importance of the request. In this message the sender assigns the highest level of importance to this request (see Sect. 3.1). In the last position there is an the index of a the speech act to which this speech act is a response. Since this speech act is not a response to any previous speech act the value is $(0,0)$.

In the responding speech act sent by Peter we have a rejection of the partner's request and a new proposal. Therefore, the message contains in fact two speech acts, namely:

$$
\begin{aligned}
& \bar{a}_{2,1}^{\beta \rightarrow \alpha}=(5,2,5,(1,1)), \\
& \bar{a}_{2,2}^{\beta \rightarrow \alpha}=(2,1,7,(0,0)) .
\end{aligned}
$$


The first speech act constitutes the rejection of the partner's offer proposed in the previous message. The value of 5 in the first position means that the intention of this act is to respond to the previous speech act, the value of 2 in the second position indicates the issue of discourse to be a negative response. The next value is the response importance level (5-quite a high level of importance), and in the last position we have $(1,1)$ which is the identifier of a speech act for which this act constitutes a response.

The second speech act by Peter is a request for accepting a new negotiation offer. The value of 2 means request, value 1 in the second position means that the issue of the discourse is an activity performance, the value 7 indicates that the level of importance is very high for the second player and $(0,0)$ in the last position identifies the requesting speech act. Again these values are zero, meaning that this speech act does not respond to any previous speech act.

The last message contains one speech act, which is an acceptance of Peter's offer by Eva and contains one speech act.

$$
\bar{a}_{3,1}^{\alpha \rightarrow \beta}=(5,1,7,(2,2))
$$

In the first position we have the intention of act encoded by the value 5 meaning that it is a response to a request, in the second position we have 1 which means that the request is being accepted. The importance level is equal to 7 and $(2,2)$ is the identifier of the speech act to which this act responds.

On the basis of this thread we can compute the levels of assertiveness and cooperativeness using formula (25). We obtain:

$$
\begin{aligned}
& d^{\text {Eva }}(\text { Assertiveness })=d^{\text {Peter }}(\text { Cooperativeness })=-1 \times \frac{5}{7} \times \frac{7}{7}=-0.71, \\
& d^{\text {Peter }}(\text { Assertiveness })=d^{\text {Eva }}(\text { Cooperativeness })=1 \times \frac{7}{7} \times \frac{7}{7}=1 .
\end{aligned}
$$

Eva received a negative response from Peter in his message, and therefore her assertiveness in this negotiation (for the current negotiation stage) is computed on the level of -0.71 . This also results in Peter's cooperativeness level equal to -0.71 , which is caused by his negative response (an uncooperative one) to Eva's request included in her first message. Then Peter obtains the assertiveness level equal to 1 , which is caused by his receiving a positive response to the request contained in the second message (he was able to realize his postulates). What is more, Eva responded positively to Peter's request contained in his message, and therefore her cooperativeness level is determined to be 1 .

\subsection{Example of Improving the Negotiation Outcome}

Let us assume that the negotiators are aiming for determining the solution in the space of two issues. For the sake of simplicity we will consider the ranges of values of two issues equal $[0,1]$. Therefore, the space of feasible solutions is:

$$
D=[0,1] \times[0,1] .
$$


Table 5 Negotiator 1 scores for $S$

\begin{tabular}{|c|c|c|c|c|c|c|c|c|c|c|}
\hline & \multicolumn{10}{|c|}{ Issue 1 options } \\
\hline & 0 & 1 & 2 & 3 & 4 & 5 & 6 & 7 & 8 & 9 \\
\hline \multicolumn{11}{|c|}{ Issue 2 options } \\
\hline 0 & 0.00 & 0.00 & 0.13 & 0.25 & 0.38 & 0.50 & 0.50 & 0.50 & 0.50 & 0.50 \\
\hline 1 & 0.10 & 0.10 & 0.23 & 0.35 & 0.48 & 0.60 & 0.60 & 0.60 & 0.60 & 0.60 \\
\hline 2 & 0.20 & 0.20 & 0.33 & 0.45 & 0.58 & 0.70 & 0.70 & 0.70 & 0.70 & 0.70 \\
\hline 3 & 0.30 & 0.30 & 0.43 & 0.55 & 0.68 & 0.80 & 0.80 & 0.80 & 0.80 & 0.80 \\
\hline 4 & 0.40 & 0.40 & 0.53 & 0.65 & 0.78 & 0.90 & 0.90 & 0.90 & 0.90 & 0.90 \\
\hline 5 & 0.50 & 0.50 & 0.62 & 0.75 & 0.88 & 1.00 & 1.00 & 1.00 & 1.00 & 1.00 \\
\hline 6 & 0.50 & 0.50 & 0.62 & 0.75 & 0.88 & 1.00 & 1.00 & 1.00 & 1.00 & 1.00 \\
\hline 7 & 0.50 & 0.50 & 0.62 & 0.75 & 0.88 & 1.00 & 1.00 & 1.00 & 1.00 & 1.00 \\
\hline 8 & 0.50 & 0.50 & 0.62 & 0.75 & 0.88 & 1.00 & 1.00 & 1.00 & 1.00 & 1.00 \\
\hline 9 & 0.50 & 0.50 & 0.62 & 0.75 & 0.88 & 1.00 & 1.00 & 1.00 & 1.00 & 1.00 \\
\hline
\end{tabular}

Table 6 Negotiator 2 scores for $S$

\begin{tabular}{|c|c|c|c|c|c|c|c|c|c|c|}
\hline & \multicolumn{10}{|c|}{ Issue 1 options } \\
\hline & 0 & 1 & 2 & 3 & 4 & 5 & 6 & 7 & 8 & 9 \\
\hline \multicolumn{11}{|c|}{ Issue 2 options } \\
\hline 0 & 1.00 & 0.94 & 0.88 & 0.81 & 0.75 & 0.69 & 0.62 & 0.56 & 0.50 & 0.50 \\
\hline 1 & 0.93 & 0.87 & 0.80 & 0.74 & 0.68 & 0.62 & 0.55 & 0.49 & 0.43 & 0.43 \\
\hline 2 & 0.86 & 0.79 & 0.73 & 0.67 & 0.61 & 0.54 & 0.48 & 0.42 & 0.36 & 0.36 \\
\hline 3 & 0.79 & 0.72 & 0.66 & 0.60 & 0.54 & 0.47 & 0.41 & 0.35 & 0.29 & 0.29 \\
\hline 4 & 0.71 & 0.65 & 0.59 & 0.53 & 0.46 & 0.40 & 0.43 & 0.28 & 0.21 & 0.21 \\
\hline 5 & 0.64 & 0.58 & 0.52 & 0.46 & 0.39 & 0.33 & 0.27 & 0.21 & 0.14 & 0.14 \\
\hline 6 & 0.57 & 0.51 & 0.45 & 0.38 & 0.32 & 0.26 & 0.20 & 0.13 & 0.07 & 0.07 \\
\hline 7 & 0.50 & 0.44 & 0.38 & 0.31 & 0.25 & 0.19 & 0.12 & 0.06 & 0.00 & 0.00 \\
\hline 8 & 0.50 & 0.44 & 0.38 & 0.31 & 0.25 & 0.19 & 0.12 & 0.06 & 0.00 & 0.00 \\
\hline 9 & 0.50 & 0.44 & 0.38 & 0.31 & 0.25 & 0.19 & 0.12 & 0.06 & 0.00 & 0.00 \\
\hline
\end{tabular}

After discretizing this set (using ten successive options for each issue) we obtain the following set of alternatives:

$$
S=\{(0,1 \cdot i, 0,1 \cdot j) \mid i, j \in\{0,1,2, \ldots, 9\}\}
$$

Using the scoring system derived in the preference analysis process we can determine the preference structure for both parties in the form of scores over the set $S$. Let us suppose that we obtained the following scores for both negotiators, as shown in Tables 5 and 6.

Having at our disposal the utility levels computed for each alternative from the set $S$ we can compute the utility profiles. Fig. 4 shows all utility profiles as black and gray 
points. The Pareto efficient frontier is represented by gray points. Let us assume that the negotiation ends with a profile evaluated as $(0.50,0.50)$, which will be a reference point for our analysis. We find the utopia point that describes the best profile for both parties simultaneously-here it is $(1,1)$. We draw the line connecting the reference point with the utopia one. The gray non-dominated point from the efficient frontier, which is nearest to the line is the compromise improvement.

\section{References}

Brzostowski J (2012) Improving negotiation outcome in the NegoManage system by the use of bargaining solution (manuscript in Polish). Econ Stud (Research Papers of University of Economics in Wrocław) 238:296-309

Brzostowski J (2011) Preference analysis approach based on formation of indifference sets for different values of extended linguistic scale. In: The 21 st international conference on multiple criteria decision making 2011, June 13-17. Jyvaskyla, Finalnd

Brzostowski J, Wachowicz T (2009) Conceptual model of eNS For supporting preference elicitation and counterpart analysis. In: Kilgour DM, Wang Q (eds) Proceedings of GDN 2009: an international conference on group decision and negotiation, Wilfried Laurier University, pp 182-186

Brzostowski J, Wachowicz T (2010) Building personality profile Of negotiator for electronic negotiations, In: Trzaskalik T, Wachowicz T (eds) Multiple criteria decision making '09. The Publisher of The University of Economics in Katowice, pp 31-46

Brzostowski J, Wachowicz T (2011) The application of linguistic scales for the description of utility in the process of preferences' analysis (manuscript in Polish). Econ Stud (Scientific Papers of University of Economics in Katowice) 97:23-40

Brzostowski J, Wachowicz T (2012) NegoManage_-a comprehensive negotiation platform. In: Teixeira de Almeida A, Costa Morais D, de Franca Dantas Daher S (eds) Group decision and negotiations 2012. Proceedings. Editoria Universitaria, Federal University of Pernambuco, Recife, pp 107-118

Brzostowski J, Wachowicz T (2012i) The analysis of negotiators' preference consistency in indifference surfaces based scoring system. In: Trzaskalik T, Wachowicz T. (eds) Multiple criteria decision making '12. The Publisher of University of Economics in Katowice (in press)

Core M, Allen J (1997) Coding dialogs with the DAMSL annotation scheme. In: Fall AAAI (ed) Symposium on communicative action in humans and machines. Cambridge, pp 28-35

Dubois D, Foulloy L, Mauris G, Prade H (2004) Probability-possibility transformations, triangular fuzzy sets and probabilistic inequalities. Reliab Comput 10:273-297

Edwards W (1977) Use of multiattribute utility measurement for social decision making. In: Bell DE, Keeney RL, Raiffa H (eds) Conflict objectives in decisions. Wiley, New York, pp 247-276

Farmer TA (1987) Testing the robustness of multiattribute utility theory in an applied setting. Decis Sci 18:178-193

Forman E, Selly MA (2001) Decision by objectives. World Scientific Publishing, Singapore

Gardner WL, Martinko MJ (1996) Using the Myers-Briggs type indicator to study managers: a literature review and research agenda. J Manag 22(1):45-83

Gupta S, Livne Z (1988) Resolving a conflict situation with a reference outcome: an axiomatic model. Manag Sci 34(11):1303-1314

Hartigan J (1975) Clustering algorithms. Wiley, New York

Keeney RL, Raiffa H (1976) Decisions with multiple objectives: preferences and value tradeoffs. Cambridge University Press, Cambridge

Kersten GE, Lai H (2007) Negotiation support and e-negotiation systems: an overview. Group Decis Negot 16:553-586

Kersten GE, Noronha SJ (1999) WWW-based negotiation support: design, implementation and use. Decis Support Syst 25:135-154

Kersten GE, Wu S (2010) Negotiation profiles and concession patterns. INR03/10

Kilmann R, Thomas KW (1983) The Thomas-Kilmann conflict mode instrument. The Organizational Development institute, Cleveland

Krantz DH, Luce RD, Suppes P, Tversky A (1971) Foundations of measurement. Academic Press, New York 
Luce RD, Tukey JW (1964) Simultaneous conjoint measurement: a new type of fundamental measurement. J Math Psychol 1:1-27

Moshkovich H, Mechitov A, Olson D (2005) Verbal decision analysis. Springer, New York

Myers LB, McCaulley MH (1985) Manual: a guide to the development and use of the Myers-Briggs type indicator. Consulting Psychologists Press, Palo Alto

Paradis N, Gettinger J, Lai H, Surboeck M, Wachowicz T (2010) E-Negotiations via Inspire 2.0: the system, users, management and projects. In: de Vreede GJ (ed) Group decision and negotiations 2010. Proceedings. University of Nebraska at Omaha, The Center for Collaboration Science, pp 155-159

Parzen E (1962) On estimation of a probability density function and mode. Ann Math Stat 33:1065-1076

Raiffa H (1982) The art and science of negotiation. The Belknap Press of Harvard University Press, Cambridge

Raiffa H, Richardson J, Metcalfe D (2003) Negotiation analysis: the science and art of collaborative decision. Harvard University Press, Cambridge

Schenkerman S (1991) Use and abuse of weights in multiple objective decision support models. Decis Sci 22:369-378

Schoop M, Jertila A, List T (2003) Negoisst: a negotiation support system for electronic business-to business negotiations in e-commerce. Data Knowl Eng 47:371-401

Searle JR (1969) Speech acts: an essay in the philosophy of language. Cambridge University Press, Cambridge

Stein JG (1989) Getting to the table: the triggers, stages, functions, and consequences of prenegotiation. Int J 44(2):475-504

Stiles WB (1992) Describing talk: a taxonomy of verbal response modes. SAGE Publications, Beverley Hills

Stroebel M (2003) Engineering electronic negotiations. Kluwer, New York

Thiessen EM, Soberg A (2003) Smartsettle described with the montreal taxonomy. Group Decis Negot 12:165-170

Thompson L (1998) The mind and heart of the negotiator. Prentice Hall, Upper Saddle River

von Neumann J, Morgenstern O (1944) Theory of games and economic behavior. Princeton University Press, Princeton

Wachowicz T, Błaszczyk P (2012) TOPSIS based approach to scoring negotiating offers in negotiation support systems. Group Decis Negot doi:10.1007/s10726-012-9299-1

Wachowicz T, Kersten GE (2009) Decisions and manners of electronic negotiation system users. In: Kłosiński KA, Biela A (eds) Proceedings of an international scientific conference "A Man And His Decisions", The Publisher of The John Paul II Catholic University Of Lublin, pp 63-74

Wachowicz T, Wu S (2010) Negotiators' strategies and their concessions. In: de Vreede GJ (ed) Group decision and negotiations 2010. Proceedings. The Center for Collaboration Science, University of Nebraska at Omaha, pp 254-259

Wood VF, Bell PA (2008) Predicting interpersonal conflict resolution styles from personality characteristics. Pers Indiv Differ 45:126-131

Zartman WI (1989) Prenegotiation: phases and functions. Int J 44(2):237-253

Zhang D, Yu PL, Wang PZ (1992) State-dependent weights in multicriteria value functions. J Optim Theory App 74:1-21 